\title{
Dynamic Stability of Double-Curvature Composite Shells under External Blast
}

\author{
Dushyanth Sirivolu and Michelle S. Hoo Fatt* \\ Department of Mechanical Engineering \\ The University of Akron \\ Akron, $\mathrm{OH}$ 44325-3903
}

October 28, 2014 (Revised March 15, 2015, June 11, 2015, August 31, 2015)

* Corresponding Author: (330) 972-6308 (phone); (330) 972-6027 (fax);

hoofatt@uakron.edu (e-mail) 


\begin{abstract}
Dynamic pulse buckling of a fully clamped, double-curvature composite shell was examined using Novozhilov nonlinear shell theory and Lagrange's equations of motion. Predictions of the shell's stable transientresponse were shown to compare well with finite element analysis using ABAQUS Explicit. Critical buckling curves were then computed for a given shell geometry using the Budiansky-Roth criterion. It was shown that the dynamic pulse buckling strength of a shell may be increased by decreasing the radius of curvature of the shell, thereby increasing its angular extent or making it deeper. Higher buckling modes are induced by making the shell deeper, and these are responsible for the increased buckling strength.
\end{abstract}

KEYWORDS:Double curvature composite shell, dynamic pulse buckling. 


\section{Introduction}

Thin-walled composite shells are commonly used to construct lightweight aerospace, military, transportation and civilian structures. When exposed to blast, these shells may undergo dynamic instability instead of stable transient and vibratory response. The specific type of dynamic instability referenced herein is dynamic pulse buckling [1]. This type of dynamic buckling is characterized by pressure pulse loading and is distinct from vibration buckling, which is characterized by oscillatory or periodic loading. Simitses [2] discusses various approaches for determining the dynamic stability of structures under sudden loading and a more recent review on the topic, including experimental studies, can be found in Singer et al. [3]. In general the dynamic stability of structures can be addressed using direct equations of motion or the Budiansky-Roth approach [4], a total energy-phase plane or the Hsu approach [5], and the total potential energy or Simitses approach [2]. In the last two approaches, lower and upper bounds of critical stability conditions are established. The Budiansky-Roth criterion simply states that instability occurs when there is a large increase in deformation response from little or no increase of load, and it involves numerical solution of non-linear coupled equations of motion. This is perhaps the most commonly used dynamic stability criterion for highly nonlinear systems which lack analytical stability criteria.

Dynamic pulse buckling due to lateral pressure pulse has been addressed for isotropic shell structures since the early 60's [6-9] and more recently for laminated composite shells, including composite sandwich shells [10-14]. In Ref. [12] the equations of motion governing transient motion of a thin composite cylinder under 
external pressure pulse loading resulted in a set of Mathieu equations for which the instability conditions are well-known. These Mathieu equations are due to parametric resonance when the hoop mode couples with specific bending modes of the cylinder. Clamped arches and single curvature shells exhibit more complicated vibration modes, and it is difficult to developclosed-form solutions forthe stability of them. Numerical solutions in combinations with one of the aforementioned stability criteria are used instead. In Gao and Hoo Fatt [13], nonlinear equations of motion were derived for clamped, single-curvature laminated composite shells exposed to external pressure pulse loading. The buckling pressures were determined using the Budiansky-Roth criterion. It was found that thicker shells were more likely to fail by fracture during stable vibratory response rather than buckling, while thinner shells were susceptible to this mode of failure. The buckling strength could also be enhanced by adjusting shell layup. Gao and Hoo Fattlater extended this study to examine local facesheet buckling or wrinkling of a single-curvature, sandwich shell [14]. A sandwich shell, consisting of two thin facesheets and a compressible core, deforms globally like a thick shell while the thin facesheet may deform locally and undergo wrinkling.

The current paper examines a more general case of pulse buckling of a thin, double-curvature composite shell that is fully clamped along its edges. Solutions are given for shells of any angular extent, i.e., both shallow and deep shells, and for pulse durations ranging from impulsive to step loading. Novozhilov nonlinear shell theory [15] is used to describe the nonlinear strain-displacement relationships, which are expanded to quadratic terms, of a double-curvature shell.The quadratic or nonlinear terms must be included in buckling analysis because they are the only means by which 
destabilizing effects are introduced into the analysis. In Gao and Hoo Fatt [14], midsurface strains and changes of curvature of a single-curvature shell were expanded to quadratic terms and this allowed for very good comparison of the transient shell responsewith ABAQUS Explicit results. It is believed that the same approach may be used to predict the transient response and dynamic stability of the double-curvature shell.

Alijani and Amabili [16]recently reviewed geometrically nonlinear shell theories as they apply to nonlinear vibrations and stability. In fact one may find an improved version of Novozhilov nonlinear shell theory in Amabili [17], although quadratic terms for the changes in curvature and twisting of the mid-surface are not given in this reference. Vibration buckling is another form of dynamic buckling, and it should be distinguished from pulse buckling, which is the topic of this paper.

An interesting study on static buckling estimates of thin shells of revolution was done by Teng and Hong [18]. Teng and Hong proposed generalized nonlinear straindisplacement relations to garner numerically-predicted static buckling loads of thin shells of revolution and showed, by comparison, the differences in results from the use of some traditional nonlinear shell theories [19-22]. Examples of traditional nonlinear shell theories include Maguerre [19] and Donnell [20] shell theories, which arespecialized or limited to shallow shells, andSanders [21] and Koiter [22] shell theories, in whichonly linear terms in changes in curvature and twisting of the midsurface are retained. Teng and Hongconcluded in their study that the omission of certain important terms was a major flaw in applying many of the traditional shell theories to buckling problems. A more recent comparison on the performance of 
nonlinear, thin shell theories to predict dynamic buckling of spherical shellsunder step loading was given by Shams and Porfiri [23].They found that the Sanders-Koiter shell theory to be accurate for all the considered shell thicknesses, while the Teng-Hong and Donnell shell theories only gave accurate results for the very thin shells. Dynamic stability under step loading was also examined by Ganapathi et al. [24] for a clamped, composite spherical cap.Their formulation was based on first-order shear deformation theory and geometric nonlinearity was introduced using von Karmanstraindisplacementrelations. An implicit numerical scheme, employing the Newmark's integration technique coupled with a modifiedNewton-Raphson iteration, was used to solve the governing equations of motion.

In this paper, we examine the dynamic stability of a double- curvature shell under general pulse loading, which is described by an exponentially-decaying function of time. Critical buckling curves, combination of peak pressures and impulses, are specifically produced for a doubly-curved, fully fixed, thin 0/90 Woven Roving Eglass/Vinyl Ester shell following this solution. The transient shell response is found using Lagrange's equation of motion. This response is then compared to finite element analysis results using ABAQUS Explicit only when the shell undergoes stable transient response. Dynamic stability of the composite shell is investigated with the BudianskyRoth criterion. A parametric study is performed to determine the influence of pulse duration, shell aspect ratio and angular extent on the buckling resistance of the shell. 


\section{Problem Formulation}

Consider a doubly-curved laminated composite shell of radius $\mathrm{R}_{1}, \mathrm{R}_{2}$, subtended angles $\psi_{0}, \theta_{0}$, and thickness $h$, subjected to uniformly-distributed pressure pulse loading as shown in Fig. 1. The external pressure pulse loading is defined as

$\mathrm{p}(\mathrm{t})=\mathrm{p}_{0} \mathrm{e}^{-\mathrm{t} / \tau}$

where $\mathrm{p}_{0}$ is the peak pressure, $\tau$ is the decay time constant and $\mathrm{t}$ is the time. The shell deforms withmid-surface transverse displacement $w\left(\xi_{1}, \xi_{2}, t\right)$, and tangential displacements $u\left(\xi_{1}, \xi_{2}, t\right)$ and $v\left(\xi_{1}, \xi_{2}, t\right)$, where $\xi_{1}, \xi_{2}$ are Gaussian curvature coordinates defined at the mid-surface of the shell in Fig. 1.

\subsection{Novozhilov nonlinear shell theory}

Novozhilov's nonlinear shallow shell theory for thin shells [15]is used to obtain the strain-displacement relations.His shell theory is valid when strains are small and rotations are arbitrary. The shell strains are given by

$\varepsilon_{1}=\varepsilon_{1 \mathrm{~m}}+\mathrm{z} \kappa_{1}$

$\varepsilon_{2}=\varepsilon_{2 \mathrm{~m}}+\mathrm{Z} \kappa_{2}$

$\gamma_{12}=\gamma_{12 \mathrm{~m}}+\mathrm{ZK}_{12}$

where $\varepsilon_{1 \mathrm{~m}}, \varepsilon_{2 \mathrm{~m}}, \gamma_{12 \mathrm{~m}}$ are the mid-surface strains and $\kappa_{1}, \kappa_{2}, \kappa_{12}$ are changes in curvature. In obtaining mid-surface strains and changes in curvatures and twisting of the mid-surface, Novozhilov assumed $\mathrm{z} / \mathrm{R}_{1}, \mathrm{z} / \mathrm{R}_{2}<<1$ by virtue of the thinness of the shell. Generalized equations for them are given in Appendix A. The reader may referto Ref. [15] for a full derivation of Novozhilov thin shell nonlinear strain- 
displacement relations. Novozhilov generalized strain-displacement expressions are expanded to quadratic or second-order terms in deformation as follows:

$$
\begin{aligned}
& \varepsilon_{1 \mathrm{~m}}=\frac{1}{\mathrm{R}_{1}} \frac{\partial \mathrm{u}}{\partial \psi}+\frac{\mathrm{w}}{\mathrm{R}_{1}}+\frac{1}{2}\left[\left(\frac{1}{\mathrm{R}_{1}} \frac{\partial \mathrm{u}}{\partial \psi}+\frac{\mathrm{w}}{\mathrm{R}_{1}}\right)^{2}+\left(\frac{1}{\mathrm{R}_{2}} \frac{\partial \mathrm{u}}{\partial \theta}\right)^{2}+\left(\frac{1}{\mathrm{R}_{1}} \frac{\partial \mathrm{w}}{\partial \psi}-\frac{\mathrm{u}}{\mathrm{R}_{1}}\right)^{2}\right] \\
& \varepsilon_{2 \mathrm{~m}}=\frac{1}{\mathrm{R}_{2}} \frac{\partial \mathrm{v}}{\partial \theta}+\frac{\mathrm{w}}{\mathrm{R}_{2}}+\frac{1}{2}\left[\left(\frac{1}{\mathrm{R}_{2}} \frac{\partial \mathrm{v}}{\partial \theta}+\frac{\mathrm{w}}{\mathrm{R}_{2}}\right)^{2}+\left(\frac{1}{\mathrm{R}_{1}} \frac{\partial \mathrm{v}}{\partial \psi}\right)^{2}+\left(\frac{1}{\mathrm{R}_{2}} \frac{\partial \mathrm{w}}{\partial \theta}-\frac{\mathrm{v}}{\mathrm{R}_{2}}\right)^{2}\right] \\
& \gamma_{12 \mathrm{~m}}=\frac{1}{\mathrm{R}_{2}} \frac{\partial \mathrm{u}}{\partial \theta}+\frac{1}{\mathrm{R}_{1}} \frac{\partial \mathrm{v}}{\partial \psi}+\frac{1}{\mathrm{R}_{1}} \frac{\partial \mathrm{v}}{\partial \psi}\left(\frac{1}{\mathrm{R}_{1}} \frac{\partial \mathrm{u}}{\partial \psi}+\frac{\mathrm{w}}{\mathrm{R}_{1}}\right)+\frac{1}{\mathrm{R}_{2}} \frac{\partial \mathrm{u}}{\partial \theta}\left(\frac{1}{\mathrm{R}_{2}} \frac{\partial \mathrm{v}}{\partial \theta}+\frac{\mathrm{w}}{\mathrm{R}_{2}}\right) \\
& +\left(\frac{1}{\mathrm{R}_{1}} \frac{\partial \mathrm{w}}{\partial \psi}-\frac{\mathrm{u}}{\mathrm{R}_{1}}\right)\left(\frac{1}{\mathrm{R}_{2}} \frac{\partial \mathrm{w}}{\partial \theta}-\frac{\mathrm{v}}{\mathrm{R}_{2}}\right) \\
& \kappa_{1}=-\frac{1}{\mathrm{R}_{1}}\left(\frac{1}{\mathrm{R}_{1}} \frac{\partial^{2} \mathrm{w}}{\partial \psi^{2}}-\frac{1}{\mathrm{R}_{1}} \frac{\partial \mathrm{u}}{\partial \psi}\right)+\frac{1}{\mathrm{R}_{1}}\left(\frac{1}{\mathrm{R}_{1}} \frac{\partial \mathrm{u}}{\partial \psi}+\frac{\mathrm{w}}{\mathrm{R}_{1}}\right)+\frac{1}{\mathrm{R}_{1}}\left(\frac{1}{\mathrm{R}_{2}} \frac{\partial \mathrm{v}}{\partial \theta}+\frac{\mathrm{w}}{\mathrm{R}_{2}}\right) \\
& -\frac{1}{\mathrm{R}_{1}^{2}} \frac{\partial^{2} \mathrm{w}}{\partial \psi^{2}}\left(\frac{1}{\mathrm{R}_{1}} \frac{\partial \mathrm{u}}{\partial \psi}+\frac{1}{\mathrm{R}_{2}} \frac{\partial \mathrm{v}}{\partial \theta}+\frac{\left(\mathrm{R}_{1}+\mathrm{R}_{2}\right)}{\mathrm{R}_{2}} \frac{\mathrm{w}}{\mathrm{R}_{1}}\right)+\frac{1}{\mathrm{R}_{1} \mathrm{R}_{2}} \frac{\partial^{2} \mathrm{u}}{\partial \psi \partial \theta}\left(\frac{1}{\mathrm{R}_{2}} \frac{\partial \mathrm{w}}{\partial \theta}-\frac{\mathrm{v}}{\mathrm{R}_{2}}\right) \\
& +\frac{1}{\mathrm{R}_{1}^{2}} \frac{\partial^{2} \mathrm{u}}{\partial \psi^{2}}\left(\frac{1}{\mathrm{R}_{1}} \frac{\partial \mathrm{w}}{\partial \psi}-\frac{\mathrm{u}}{\mathrm{R}_{1}}\right)+\frac{1}{\mathrm{R}_{1}^{2}} \frac{\partial \mathrm{u}}{\partial \psi}\left(\frac{3}{\mathrm{R}_{2}} \frac{\partial \mathrm{v}}{\partial \theta}+\frac{2}{\mathrm{R}_{1}} \frac{\partial \mathrm{u}}{\partial \psi}\right)+\frac{2}{\mathrm{R}_{1}}\left(\frac{1}{\mathrm{R}_{1}} \frac{\partial \mathrm{w}}{\partial \psi}\right)^{2} \\
& -\frac{1}{\mathrm{R}_{1}}\left(\frac{1}{\mathrm{R}_{1}} \frac{\partial \mathrm{v}}{\partial \psi}\right)\left(\frac{1}{\mathrm{R}_{2}} \frac{\partial \mathrm{u}}{\partial \theta}\right)+\frac{\mathrm{u}}{\mathrm{R}_{1}^{2}}\left(-\frac{3}{\mathrm{R}_{1}} \frac{\partial \mathrm{w}}{\partial \psi}+\frac{\mathrm{u}}{\mathrm{R}_{1}}\right) \\
& +\frac{\mathrm{w}}{\mathrm{R}_{1}^{2}}\left(\frac{3\left(\mathrm{R}_{1}+\mathrm{R}_{2}\right)}{\mathrm{R}_{2}}\left(\frac{1}{\mathrm{R}_{1}} \frac{\partial \mathrm{u}}{\partial \psi}\right)+\frac{2}{\mathrm{R}_{2}} \frac{\partial \mathrm{v}}{\partial \theta}+\frac{\left(2 \mathrm{R}_{1}+\mathrm{R}_{2}\right)}{\mathrm{R}_{2}} \frac{\mathrm{w}}{\mathrm{R}_{1}}\right)
\end{aligned}
$$




$$
\begin{aligned}
& \kappa_{2}=-\frac{1}{\mathrm{R}_{2}}\left(\frac{1}{\mathrm{R}_{2}} \frac{\partial^{2} \mathrm{w}}{\partial \theta^{2}}-\frac{1}{\mathrm{R}_{2}} \frac{\partial \mathrm{v}}{\partial \theta}\right)+\frac{1}{\mathrm{R}_{2}}\left(\frac{1}{\mathrm{R}_{2}} \frac{\partial \mathrm{v}}{\partial \theta}+\frac{\mathrm{w}}{\mathrm{R}_{2}}\right)+\frac{1}{\mathrm{R}_{2}}\left(\frac{1}{\mathrm{R}_{1}} \frac{\partial \mathrm{u}}{\partial \psi}+\frac{\mathrm{w}}{\mathrm{R}_{1}}\right) \\
& -\frac{1}{\mathrm{R}_{2}^{2}} \frac{\partial^{2} \mathrm{w}}{\partial \theta^{2}}\left(\frac{1}{\mathrm{R}_{2}} \frac{\partial \mathrm{v}}{\partial \theta}+\frac{1}{\mathrm{R}_{1}} \frac{\partial \mathrm{u}}{\partial \psi}+\frac{\left(\mathrm{R}_{1}+\mathrm{R}_{2}\right)}{\mathrm{R}_{1}} \frac{\mathrm{w}}{\mathrm{R}_{2}}\right)+\frac{1}{\mathrm{R}_{1} \mathrm{R}_{2}} \frac{\partial^{2} \mathrm{v}}{\partial \psi \partial \theta}\left(\frac{1}{\mathrm{R}_{1}} \frac{\partial \mathrm{w}}{\partial \psi}-\frac{\mathrm{u}}{\mathrm{R}_{1}}\right) \\
& +\frac{1}{\mathrm{R}_{2}^{2}} \frac{\partial^{2} \mathrm{v}}{\partial \theta^{2}}\left(\frac{1}{\mathrm{R}_{2}} \frac{\partial \mathrm{w}}{\partial \theta}-\frac{\mathrm{v}}{\mathrm{R}_{2}}\right)+\frac{1}{\mathrm{R}_{2}^{2}} \frac{\partial \mathrm{v}}{\partial \theta}\left(\frac{3}{\mathrm{R}_{1}} \frac{\partial \mathrm{u}}{\partial \psi}+\frac{2}{\mathrm{R}_{2}} \frac{\partial \mathrm{v}}{\partial \theta}\right)+\frac{2}{\mathrm{R}_{2}}\left(\frac{1}{\mathrm{R}_{2}} \frac{\partial \mathrm{w}}{\partial \theta}\right)^{2} \\
& -\frac{1}{\mathrm{R}_{2}}\left(\frac{1}{\mathrm{R}_{1}} \frac{\partial \mathrm{v}}{\partial \psi}\right)\left(\frac{1}{\mathrm{R}_{2}} \frac{\partial \mathrm{u}}{\partial \theta}\right)+\frac{\mathrm{v}}{\mathrm{R}_{2}^{2}}\left(-\frac{3}{\mathrm{R}_{2}} \frac{\partial \mathrm{w}}{\partial \theta}+\frac{\mathrm{v}}{\mathrm{R}_{2}}\right) \\
& +\frac{\mathrm{w}}{\mathrm{R}_{2}^{2}}\left(\frac{3\left(\mathrm{R}_{1}+\mathrm{R}_{2}\right)}{\mathrm{R}_{1}}\left(\frac{1}{\mathrm{R}_{2}} \frac{\partial \mathrm{v}}{\partial \theta}\right)+\frac{2}{\mathrm{R}_{1}} \frac{\partial \mathrm{u}}{\partial \psi}+\frac{\left(\mathrm{R}_{1}+2 \mathrm{R}_{2}\right)}{\mathrm{R}_{1}} \frac{\mathrm{w}}{\mathrm{R}_{2}}\right) \\
& \kappa_{12}=-\frac{2}{\mathrm{R}_{1} \mathrm{R}_{2}} \frac{\partial^{2} \mathrm{w}}{\partial \theta \partial \psi}+\frac{1}{\mathrm{R}_{1} \mathrm{R}_{2}}\left(\frac{\partial \mathrm{u}}{\partial \theta}+\frac{\partial \mathrm{v}}{\partial \psi}\right)-\frac{2}{\mathrm{R}_{1} \mathrm{R}_{2}} \frac{\partial^{2} \mathrm{w}}{\partial \theta \partial \psi}\left(\frac{1}{\mathrm{R}_{1}} \frac{\partial \mathrm{u}}{\partial \psi}+\frac{1}{\mathrm{R}_{2}} \frac{\partial \mathrm{v}}{\partial \theta}+\frac{\left(\mathrm{R}_{1}+\mathrm{R}_{2}\right) \mathrm{w}}{\mathrm{R}_{1} \mathrm{R}_{2}}\right) \\
& +\left(\frac{1}{\mathrm{R}_{2}^{2}} \frac{\partial^{2} \mathrm{u}}{\partial \theta^{2}}+\frac{1}{\mathrm{R}_{1} \mathrm{R}_{2}} \frac{\partial^{2} \mathrm{v}}{\partial \theta \partial \psi}\right)\left(\frac{1}{\mathrm{R}_{2}} \frac{\partial \mathrm{w}}{\partial \theta}-\frac{\mathrm{v}}{\mathrm{R}_{2}}\right)+\left(\frac{1}{\mathrm{R}_{1}^{2}} \frac{\partial^{2} \mathrm{v}}{\partial \psi^{2}}+\frac{1}{\mathrm{R}_{1} \mathrm{R}_{2}} \frac{\partial^{2} \mathrm{u}}{\partial \theta \partial \psi}\right)\left(\frac{1}{\mathrm{R}_{1}} \frac{\partial \mathrm{w}}{\partial \psi}-\frac{\mathrm{u}}{\mathrm{R}_{1}}\right) \\
& +\frac{\left(\mathrm{R}_{1}+\mathrm{R}_{2}\right)}{\mathrm{R}_{1} \mathrm{R}_{2}}\left(\frac{1}{\mathrm{R}_{1}} \frac{\partial \mathrm{u}}{\partial \psi}+\frac{1}{\mathrm{R}_{2}} \frac{\partial \mathrm{v}}{\partial \theta}\right)\left(\frac{1}{\mathrm{R}_{2}} \frac{\partial \mathrm{u}}{\partial \theta}+\frac{1}{\mathrm{R}_{1}} \frac{\partial \mathrm{v}}{\partial \psi}\right)+\frac{2\left(\mathrm{R}_{1}+\mathrm{R}_{2}\right)}{\mathrm{R}_{1} \mathrm{R}_{2}}\left(\frac{1}{\mathrm{R}_{2}} \frac{\partial \mathrm{w}}{\partial \theta}\right)\left(\frac{1}{\mathrm{R}_{1}} \frac{\partial \mathrm{w}}{\partial \psi}\right) \\
& +\frac{\left(\mathrm{R}_{1}+\mathrm{R}_{2}\right)^{2}}{\mathrm{R}_{1} \mathrm{R}_{2}} \frac{\mathrm{w}}{\mathrm{R}_{1} \mathrm{R}_{2}}\left(\frac{1}{\mathrm{R}_{2}} \frac{\partial \mathrm{u}}{\partial \theta}+\frac{1}{\mathrm{R}_{1}} \frac{\partial \mathrm{v}}{\partial \psi}\right)-\frac{\left(\mathrm{R}_{1}+2 \mathrm{R}_{2}\right)}{\mathrm{R}_{1} \mathrm{R}_{2}}\left(\frac{1}{\mathrm{R}_{2}} \frac{\partial \mathrm{w}}{\partial \theta}\right) \frac{\mathrm{u}}{\mathrm{R}_{1}} \\
& -\frac{\left(2 \mathrm{R}_{1}+\mathrm{R}_{2}\right)}{\mathrm{R}_{1} \mathrm{R}_{2}}\left(\frac{1}{\mathrm{R}_{1}} \frac{\partial \mathrm{w}}{\partial \psi}\right) \frac{\mathrm{v}}{\mathrm{R}_{2}}+\frac{\left(\mathrm{R}_{1}+\mathrm{R}_{2}\right)}{\mathrm{R}_{1} \mathrm{R}_{2}} \frac{\mathrm{u}}{\mathrm{R}_{1}} \frac{\mathrm{v}}{\mathrm{R}_{2}}
\end{aligned}
$$

Amabili [17] has proposed a variant of the above mid-surface strains based on by retaining $\mathrm{z} / \mathrm{R}_{1}, \mathrm{z} / \mathrm{R}_{2}$ and neglecting $\left(\mathrm{z} / \mathrm{R}_{1}\right)^{2},\left(\mathrm{z} / \mathrm{R}_{2}\right)^{2}$ instead. These have been applied with only the linear curvature and twisting retained to solve nonlinear vibrations of double-curvature shells [25], including shells with shear deformations [26]. Both strain-displacement forms are acceptable provided the shell is very thin and deflections are a few times the shell thickness. However, for large deflection analysis involving snap through buckling, the quadratic or second-order terms describing changes in curvature and twisting become necessary [14]. 


\section{Nonlinear Equations of Motion}

The boundary conditions for a shell that is clamped at the four edges are $\mathrm{w}=\frac{\partial \mathrm{w}}{\partial \psi}=\mathrm{u}=\mathrm{v}=0$ at $\psi=0, \psi_{0}$ and $\mathrm{w}=\frac{\partial \mathrm{w}}{\partial \theta}=\mathrm{u}=\mathrm{v}=0$ at $\theta=0, \theta_{0}$. In order to be consistent with the above clamped boundary conditions, deflections are expressed in by the following double Fourier series:

$$
\begin{aligned}
& \mathrm{w}=\sum_{\mathrm{n}=0}^{\mathrm{N}} \sum_{\mathrm{m}=0}^{\mathrm{M}} \mathrm{a}_{\mathrm{mn}}\left(1-\cos \frac{2 \pi \psi}{\psi_{0}}\right)\left(1-\cos \frac{2 \pi \theta}{\theta_{0}}\right) \cos \frac{\mathrm{m} \pi \psi}{\psi_{0}} \cos \frac{\mathrm{n} \pi \theta}{\theta_{0}} \\
& \mathrm{u}=\sum_{\mathrm{n}=1 \mathrm{~m}=1}^{\mathrm{N}} \sum_{\mathrm{mn}}^{\mathrm{M}} \mathrm{b}_{\mathrm{m}} \sin \frac{\mathrm{m} \pi \psi}{\psi_{0}} \sin \frac{\mathrm{n} \pi \theta}{\theta_{0}} \\
& \mathrm{v}=\sum_{\mathrm{n}=\mathrm{lm}=1}^{\mathrm{N}} \sum_{\mathrm{mn}}^{\mathrm{M}} \mathrm{c}_{\mathrm{mn}} \sin \frac{\mathrm{m} \pi \psi}{\psi_{0}} \sin \frac{\mathrm{n} \pi \theta}{\theta_{0}}
\end{aligned}
$$

Geometric imperfections are not considered in the above series. It should be mentioned that power law functions have also been used to describe displacement of a clamped shell by Abe et al. [27].

The dynamic response of the sandwich shell is found by satisfying Lagrange's equations of motion:

$\frac{\mathrm{d}}{\mathrm{dt}}\left(\frac{\partial \mathrm{T}}{\partial \dot{\mathrm{q}}_{\mathrm{mn}}}\right)-\frac{\partial \mathrm{T}}{\partial \mathrm{q}_{\mathrm{mn}}}+\frac{\partial \mathrm{U}}{\partial \mathrm{q}_{\mathrm{mn}}}=\mathrm{Q}_{\mathrm{mn}}$

where $\mathrm{T}$ and $\mathrm{U}$ are the kinetic and strain energy of the shell, $\mathrm{q}_{\mathrm{mn}}$ are generalized coordinates $\left(\mathrm{a}_{\mathrm{mn}}, \mathrm{b}_{\mathrm{mn}}\right.$, and $\left.\mathrm{c}_{\mathrm{mn}}\right), \dot{\mathrm{q}}_{\mathrm{mn}}$ are generalized velocities, and $\mathrm{Q}_{\mathrm{mn}}$ are generalized forces. 
The kinetic energy is

$$
\mathrm{T}=\frac{1}{2} \rho \int_{0}^{\psi_{0}} \int_{0}^{\theta_{0}} \int_{-\mathrm{h} / 2}^{\mathrm{h} / 2}\left(\dot{\mathrm{u}}^{2}+\dot{\mathrm{v}}^{2}+\dot{\mathrm{w}}^{2}\right) \mathrm{R}_{1} \mathrm{~d} \psi \mathrm{R}_{2} \mathrm{~d} \theta \mathrm{dz}
$$

where $\rho$ is the mass density of the shell. Rotary inertia is neglected also because of the thinness assumption, $\mathrm{z} / \mathrm{R}_{1}, \mathrm{z} / \mathrm{R}_{2}<<1$.

For an orthotropic shell, the elastic strain energy is given by

$$
\begin{aligned}
\mathrm{U}=\frac{1}{2} \int_{0}^{\psi_{0}} \int_{0}^{\theta_{0}}\left(\mathrm{~A}_{11} \varepsilon_{1 \mathrm{~m}}^{2}+\mathrm{A}_{22} \varepsilon_{2 \mathrm{~m}}^{2}+2 \mathrm{~A}_{12} \varepsilon_{1 \mathrm{~m}} \varepsilon_{2 \mathrm{~m}}+\mathrm{A}_{66} \gamma_{12 \mathrm{~m}}^{2}\right. \\
\left.+\mathrm{D}_{11} \kappa_{1}^{2}+\mathrm{D}_{22} \kappa_{2}^{2}+2 \mathrm{D}_{12} \kappa_{1} \kappa_{2}+\mathrm{D}_{66} \kappa_{12}^{2}\right) \mathrm{R}_{1} \mathrm{~d} \psi \mathrm{R}_{2} \mathrm{~d} \theta
\end{aligned}
$$

where $A_{i j}$ and $D_{i j}$ are the membrane and bending stiffness of the shell.

Generalized forces $\mathrm{Q}_{\mathrm{mn}}$ are obtained from virtual work $\delta \mathrm{W}$ :

$\mathrm{Q}_{\mathrm{mn}}=\frac{\partial(\delta \mathrm{W})}{\partial\left(\delta \mathrm{q}_{\mathrm{mn}}\right)}$

For a uniformly distributed external pressure pulse,

$$
\delta \mathrm{W}=\int_{0}^{\psi_{0}} \int_{0}^{\theta_{0}} \mathrm{p}\left(\xi_{1}, \xi_{2}, \mathrm{t}\right) \delta \mathrm{w} \mathrm{R}_{1} \mathrm{~d} \psi \mathrm{R}_{2} \mathrm{~d} \theta
$$

Hence,

$$
\mathrm{Q}_{\mathrm{mn}}=\mathrm{p}(\mathrm{t}) \int_{0}^{\psi_{0}} \int_{0}^{\theta_{0}}\left(1-\cos \frac{2 \pi \psi}{\psi_{0}}\right)\left(1-\cos \frac{2 \pi \theta}{\theta_{0}}\right) \cos \frac{\mathrm{m} \pi \psi}{\psi_{0}} \cos \frac{\mathrm{n} \pi \theta}{\theta_{0}} \mathrm{R}_{1} \mathrm{~d} \psi \mathrm{R}_{2} \mathrm{~d} \theta
$$

Note that the function for transverse deflection w is not orthogonal and this will lead to coupled,nonlinear equations of motion upon satisfying Lagrange's equations of motion. The following section describes the forced response of the shell subjected to a pressure 
pulse that causes stable vibratory response.

\section{Stable Forced Response}

An orthotropic shell made of 0/90 Woven Roving E-Glass/Vinyl Ester with thickness $h=2.5 \mathrm{~mm}$, radii $R_{1}=R_{2}=396 \mathrm{~mm}$ and subtended angles $\psi_{0}=\theta_{0}=40$ deg is considered. Laminate properties for the 0/90 Woven Roving E-Glass/Vinyl Ester were taken from Boh et al. [28] and are shown in Table 1. This shell is subjected to external pressure pulse loading with peak pressure $\mathrm{p}_{0}=0.9 \mathrm{MPa}$ and time decay constant $\tau=1 \mathrm{~ms}$.

Table 1 Material properties of 0/90 Woven Roving E-glass/Vinyl Ester.

\begin{tabular}{|c|c|}
\hline Material & $\begin{array}{c}\text { 0/90 Woven Roving } \\
\text { E-Glass/Vinyl Ester }\end{array}$ \\
\hline Density $\left(\mathrm{kg} / \mathrm{m}^{3}\right)$ & 1,391 \\
\hline $\mathrm{E}_{11}(\mathrm{GPa})$ & 17 \\
\hline $\mathrm{E}_{22}(\mathrm{GPa})$ & 17 \\
\hline $\mathrm{E}_{33}(\mathrm{GPa})$ & 7.48 \\
\hline$v_{12}$ & 0.13 \\
\hline$v_{23}$ & 0.28 \\
\hline$v_{13}$ & 0.28 \\
\hline$v_{31}$ & 0.12 \\
\hline $\mathrm{G}_{12}=\mathrm{G}_{21}(\mathrm{GPa})$ & 4.0 \\
\hline $\mathrm{G}_{23}=\mathrm{G}_{32}(\mathrm{GPa})$ & 1.73 \\
\hline $\mathrm{G}_{13}=\mathrm{G}_{31}(\mathrm{GPa})$ & 1.73 \\
\hline
\end{tabular}




\subsection{Solution of Lagrange's Equations of Motion}

The coupled equations of motion were solved with MATLAB using ode23tb solver and the MATLAB parallel computing tool box. The MATLAB solver ode23tbis based on an implementation of TR-BDF2, an implicit Runge-Kutta formula with a first stage that is a trapezoidal rule step and a second stage that is a backward differentiation formula of order 2, and has no numerical damping. Theabsolute and relative tolerances in the MATLAB program were chosen to be $1 \mathrm{e}^{-3}$ and $1 \mathrm{e}^{-3}$, respectively. The program ran for a step time of $\mathrm{t}=3 \mathrm{~ms}$ with various numbers of terms in the double Fourier series. Figure 2(a) shows the transverse deflection in the middle of shell when $\mathrm{N}=\mathrm{M}=4$, $\mathrm{N}=\mathrm{M}=6$, and $\mathrm{N}=\mathrm{M}=8$. The corresponding deflection profile of the shell at 0.9 ms along $y=b / 2$ is shown Fig. 2(b). Thus it was concluded from these results that $\mathrm{N}=\mathrm{M}=6$ in the double Fourier series should provide adequate accuracy.Individual contributions of the Fourier components when $\mathrm{N}=\mathrm{M}=6$ are plotted in Appendix B so that the reader may get a sense of how rapidly the double series converges.

\subsection{Finite Element Analysis}

Finite element analysis using ABAQUS Explicit Version 6.13 was used to corroborate results from the analytical model. The FEA model for the double curvature shell is shown in Fig. 3. The dimensions of the shell are the same as in the above example. All sides of the shell were encastre or fully fixed. Three-dimensional, continuum eight node (C3D8) or brick elements were chosen. Three solid elements were used in the thickness direction, and a total of 314,928 elements were needed to assure accurate (converged) FEA results.Solid elements were used instead of shell elements in order to 
obtain the most accurate FEA prediction. Conventional and continuum shell elements were not used in this particular application because their nonlinear behaviors are very much dependent on the kinematics and constraints from which these elements were derived.

The shell materialwas assumed to be orthotropic, linear elastic with properties of E-Glass/Vinyl Ester Woven Roving. A uniformly distributed pressure, expressed by Eq. (1) where $\mathrm{p}_{0}=0.9 \mathrm{MPa}$ and $\tau=1 \mathrm{~ms}$, was applied to the shell. A Dynamic, Explicit step with nonlinear geometry was run, and the default values for the linear and quadratic bulk viscosity of 0.06 and 1.2 were used.

Solutions for the mid-surface deflections of panel center are shown in Fig.4(a), and these are compared to predictions using Lagrange's equations of motion over a period of $3 \mathrm{~ms}$. Overall the stable forced response from FEA and Lagrange's equations of motion were found to be consistent in terms of center panel deflections and vibrations up to $1.5 \mathrm{~ms}$. The maximum deflection predicted from nonlinear shell theory is $11.4 \mathrm{~mm}$, which is over four times the shell thickness, and it is of the same magnitude as that obtained from FEA. One should not expect an exact correlation between the transient response using two-dimensional, nonlinear shell theory and threedimensional FEA with ABAQUS Explicit because of differences in formulations. In particular, the 3D solid continuum elements (C3D8) are not subjected to the plane stress assumption that is inherent in Novozhilov thin shell theory. Transverse or through-thickness properties and their effect on dynamic behavior are taken into consideration in the FEA, while they are ignored in the thin shell of the analytical model. The static bucking response of the shell is examined in Appendix $\mathrm{C}$ to 
eliminate thesedynamic effects and further validate the analytical solution with Novozhilov thin shell theory.

The deflection profiles at 0.9 msalong the panel $(\mathrm{y}=\mathrm{b} / 2)$ are also compared with respect to FEA and the Lagrange's equations of motion methods in Fig. 4(b). At 0.9 ms,both FEA and Lagrange's equations of motion give the same panel center deflection and appear to be the most synchronized with respect to dynamic mode so this is a good time to compare deflection shapes. Since the deflections are of similar shapes (capturing the similar vibration modes), one can conclude from this comparison that Novozhilov nonlinear shell theory and the associated equations of motion were accurate in predicting the transient shell response.

\section{Dynamic Instability}

Dynamic instability of the shell was assessed using the Budiansky-Roth buckling criterion [4]. The application of this criterion requires solving the equations of motion for different values of peak pressure $\mathrm{p}_{0}$, monitoring the significant change in shell responsesand determining the critical peak pressure $\mathrm{p}_{\mathrm{cr}}$. The time variation of center deflection of the shell with various peak pressures and a decay constant $\tau=1 \mathrm{~ms}$, are shown in Fig. 5(a). One may observe from this plot that there is a sudden change in vibratory behaviour between pressure amplitudes $1.5 \mathrm{MPa}$ and $1.75 \mathrm{MPa}$, where the maximum deflection changes from $18 \mathrm{~mm}$ to $55.5 \mathrm{~mm}$.

A plot of the peak pressure and the maximum deflection during the forced vibration response produces a stability curve for the $1 \mathrm{~ms}$ decay constant as shown in Fig. 5(b). Now it is clear to see from Fig. 5(b) that the shell has experience a sudden 
change in vibratory response when $\mathrm{p}_{0}=1.5 \mathrm{MPa}$ and $\tau=1 \mathrm{~ms}$. This sudden "jump" in deflection is the onset of dynamic buckling and the pressure load at which this takes place is the buckling load. For pressure amplitudes above $\mathrm{p}_{\mathrm{cr}}$, the shell experiences snap-through instability. After snap-through, the shell experiences stable response because of membrane stiffening.

\subsection{Critical buckling curves}

The critical buckling curve allows one to examine the buckling strength of the shell for any load that is characterized by an exponential pulse. The exponential decay constant $\tau$ determines whether the pressure pulse loading is impulsive, dynamic or quasi-dynamic. Again consider the 0/90 Woven Roving E-Glass/Vinyl Ester shell thickness $\mathrm{h}=2.5 \mathrm{~mm}$, radii $\mathrm{R}_{1}=\mathrm{R}_{2}=\mathrm{R}=396 \mathrm{~mm}$ and subtended angles $\psi_{0}=\theta_{0}=40 \mathrm{deg}$. The combination of critical peak pressures and impulses for decay constant $0.001,0.01,0.1,1,10$ and $100 \mathrm{~ms}$ are shownin Fig. 6(a), where bothaxes are on logarithmic scale. The insert graph of Fig. 6(a) indicates how the load transients change with increasing decaying constant, $\tau$. Notice that a general trend of this curve is that (a) the critical buckling pressure asymptotically approaches a limiting value when the pressure pulse decay constant is very large, i.e, step loading response and (b) critical buckling impulse asymptotically approaches a limiting value when the decay constant is very small, i.e., impulse response.

Stability curves used to determine the critical buckling curves at four different load decay constants are shown in Fig. 6(b). The longer duration decay time constant pressure pulses give a sharper indication of shell instability. As the decay constant 
decreases, the critical buckling pressure rises in value and the difference in deflections at the bifurcation point diminishes. At a decay constant of $0.1 \mathrm{~ms}$, there is more of a change in the slope or stiffness the instability point. Results for decay constants less than $0.1 \mathrm{~ms}$ are not shown in this graph because the pressure loads are too high.

\subsection{Influence of shell geometry}

The buckling strength of the double curvature shell is controlled by two geometric parameters: span and curvature. A parametric study was done to examine both. In all cases $R_{1}=R_{2}=R$ and $\psi_{0}=\theta_{0}$ for simplicity. In the first study, the shell radius was fixed at $\mathrm{R}=396 \mathrm{~mm}$, i.e. $\mathrm{R} / \mathrm{h}=158.4$. Three different spans were then considered by making $\theta_{0}=20,40,80 \mathrm{deg}$. A diagram explaining this parametric study is given in Fig. 7(a). It should be noted that a 20-deg shell is shallow, while an 80-deg shell is rather deep shell. Figure 7(b) shows critical buckling curves for the various span-to-thickness ratios or angular extent. Clearly buckling strength increases with increasing angular extent or depth of the shell.

In the second parametric study, the span was fixed at $a=276.5 \mathrm{~mm}$, i.e. $\mathrm{a} / \mathrm{h}=110.6$. Three different shell radius-to-thickness ratios were then considered. As indicated in Fig. 8(a), the shell angular extent changes in order to keep the same span. Now the shell with the smallest radius of curvature is the deepest shell, and the shell with the largest radius curvature is the shallowest shell. Critical buckling curves for the three geometries are shown in Fig. 8(b), where it is clearly seen that buckling strength increases with curvature or decreasing radius of curvature for a fixed span. The 80-deg

shell is a deep shell, and it resists more of the pressure from in-plane membrane action 
than the 40- and 20-deg shells. The above conclusion was experimentally verified by Kumar et al. [29], when they conducted shock tube tests on carbon-epoxy shells.

An explanation for the increased buckling strength with increasing angular extent can be given by examining the deformation and buckling modes for each shell when they are subjected to a pulse with 1ms-decay in Figs. 9(a)-(c) and Figs. 10(a)-(c). The shells in Figs. 9(a)-(c) are taken from the first parametric study (varying a/h), while the shells in Figs. 10(a)-(c) are from the second parametric study (varying R/h). The 20 deg shells show a definite snap-through buckling mode very similar to quasi-static buckling modes. However, the 40 and 80 deg shells buckle with higher mode numbers. The 80 deg shell with $\mathrm{a} / \mathrm{h}=110.6$ and $\mathrm{R} / \mathrm{h}=79.2$ (Fig. 10(c)) actually buckles with Mode 4, while the $80 \mathrm{deg}$ shell with $\mathrm{a} / \mathrm{h}=221.2$ and $\mathrm{R} / \mathrm{h}=158.4$ (Fig. 9(c)) buckles with Mode 2 owing to longer span and higher radius of curvature to maintain the same $80 \mathrm{deg}$ angle. Critical buckling curves for the $80 \mathrm{deg}$ shell with $\mathrm{a} / \mathrm{h}=110.6$ and $\mathrm{R} / \mathrm{h}=79.2$ are higher than the critical buckling curves for the $80 \mathrm{deg}$ shell with $\mathrm{a} / \mathrm{h}=221.2$ and $\mathrm{R} / \mathrm{h}=158.4$ regardless of the exponential decay constant of the pressure pulse.

The parametric study in Figs. 9(a)-(c) and Figs. 10(a)-(c) reveals that higher buckling modes are excited as the angular extent of the shell increases. Shams and Porfiri [23] have looked at thin spherical shells subjected to step loading and found shell thickness can have an influence on dynamic buckling modes. They noticed that as the shell thickness increases, the wavelength of the buckling pattern decreases so that the shell buckles with fewer modes. Buckling with higher mode numbers is a type of wrinkling instability that is often observed in cylindrical shells under pressure pulse loading $[1,12]$. These higher modes are responsible for the increased buckling strength 
because they are associated with higher bending resistance of the shell. The parametric study suggests that the dynamic pulse buckling resistance of a curved panel may be increased by increasing its angular extent or making the shell deeper, whether by increasing span for a fixed radius of curvature or decreasing the radius of curvature of the shell for a fixed span.

\section{Concluding Remarks}

Dynamic pulse buckling of a fully clamped, double-curvature composite shell was examined in this paper. Novozhilov nonlinear shell theory was used to capture the large deformation response of the shell under an exponentially decaying pressure pulse. Equations of motion were derived using a Lagrangian approach. The clamped boundary conditions imposed on the shell resulted in coupling of nonlinear differential equations because of non-orthogonal modes in the transverse deflections. Predictions of the shell's stable vibratory response were shown to compare relatively well with finite element analysis using ABAQUS Explicit.

Critical buckling curves were computed for a given shell geometry using the Budiansky-Roth criterion. It was shown that the dynamic pulse buckling strength of a curved panel may be increased by increasing its angular extent or making the shell deeper, whether by increasing span for a fixed radius of curvature or decreasing the radius of curvature of the shell for a fixed span. Higher buckling modes are induced by increasing the angular extent of the shell or making the shell deeper, and these higher buckling modes are responsible for the increasing the buckling strength because they are associated with higher bending resistance of the shell. 


\section{Acknowledgement}

The authors would like to acknowledge financial support from Dr. Yapa Rajapakse at the Office of Naval Research under Grant N00014-11-1-0485. This work was also supported in part by an allocation of computing time from the Ohio Supercomputer Center. 


\section{Appendix A}

\section{Novozhilov Nonlinear Shell Theory}

In Chapter VI of Reference [15], Novozhilov presents a theory of deformations for thin shells using Gaussian curvilinear coordinates to describe the mid-surface of the shell.This theory is valid for small strains and arbitrary rotations (arbitrary in the sense that rotations still give small strains). This section summarizes general straindisplacement relations from Novozhilov nonlinear shell theory. A full derivation of Novozhilov thin shell nonlinear strain-displacement relations may be found in Ref. [15].

The shell coordinate system is described in Fig. 1. The shell deforms with midsurface radial displacement $\mathrm{w}\left(\xi_{1}, \xi_{2}, \mathrm{t}\right)$, and tangential displacements $\mathrm{u}\left(\xi_{1}, \xi_{2}, \mathrm{t}\right)$ and $\mathrm{v}\left(\xi_{1}, \xi_{2}, \mathrm{t}\right)$, where $\xi_{1}, \xi_{2}$ are Gaussian curvature coordinates defined at the mid-surface of the shell in Fig. 1.Novozhilov assumed fibers normal to mid-surface do not elongate, and remain normal before and after deformation. With this assumption, transverse normal and shear strains are neglected, and the remaining strains are represented by

$$
\begin{aligned}
& \varepsilon_{1}=\varepsilon_{1 \mathrm{~m}}+\mathrm{z \kappa}_{1} \\
& \varepsilon_{2}=\varepsilon_{2 \mathrm{~m}}+\mathrm{z \kappa}_{2} \\
& \gamma_{12}=\gamma_{12 \mathrm{~m}}+\mathrm{z \kappa}_{12}
\end{aligned}
$$

where $\varepsilon_{1 \mathrm{~m}}, \varepsilon_{2 \mathrm{~m}}, \gamma_{12 \mathrm{~m}}$ are mid-surface normal and shear strains and $\kappa_{1}, \kappa_{2}, \kappa_{12}$ are variations in curvature and twisting of the mid-surface induced by the deformations. 
Based on the thinness of the shell, Nonvozhilov assumed $1+\mathrm{z} / \mathrm{R}_{1} \approx 1+\mathrm{z} / \mathrm{R}_{2} \approx 1$, he represented the mid-surface strains andvariations in curvature and twisting by

$$
\begin{aligned}
& \varepsilon_{1 \mathrm{~m}}=\widehat{\mathrm{e}}_{11}+\frac{1}{2}\left(\hat{\mathrm{e}}_{11}^{2}+\hat{\mathrm{e}}_{12}^{2}+\hat{\mathrm{e}}_{13}^{2}\right) \\
& \varepsilon_{2 \mathrm{~m}}=\widehat{\mathrm{e}}_{22}+\frac{1}{2}\left(\hat{\mathrm{e}}_{21}^{2}+\hat{\mathrm{e}}_{22}^{2}+\hat{\mathrm{e}}_{23}^{2}\right) \\
& \gamma_{12 \mathrm{~m}}=\widehat{\mathrm{e}}_{12}+\widehat{\mathrm{e}}_{21}+\widehat{\mathrm{e}}_{11} \widehat{\mathrm{e}}_{21}+\widehat{\mathrm{e}}_{22} \widehat{\mathrm{e}}_{12}+\widehat{\mathrm{e}}_{13} \widehat{\mathrm{e}}_{23} \\
& \kappa_{1}=\left(1+\widehat{\mathrm{e}}_{11}\right) \mathrm{k}_{11}+\widehat{\mathrm{e}}_{12} \mathrm{k}_{12}+\widehat{\mathrm{e}}_{13} \mathrm{k}_{13} \\
& \kappa_{2}=\left(1+\widehat{\mathrm{e}}_{22}\right) \mathrm{k}_{22}+\widehat{\mathrm{e}}_{21} \mathrm{k}_{21}+\widehat{\mathrm{e}}_{23} \mathrm{k}_{23} \\
& \kappa_{12}=\left(1+\widehat{\mathrm{e}}_{11}\right) \mathrm{k}_{21}+\left(1+\widehat{\mathrm{e}}_{22}\right) \mathrm{k}_{12}+\widehat{\mathrm{e}}_{21} \mathrm{k}_{11}+\widehat{\mathrm{e}}_{12} \mathrm{k}_{22}+\widehat{\mathrm{e}}_{23} \mathrm{k}_{13}+\widehat{\mathrm{e}}_{13} \mathrm{k}_{23}
\end{aligned}
$$

where

$$
\begin{aligned}
& \widehat{\mathrm{e}}_{11}=\frac{1}{\mathrm{R}_{1}} \frac{\partial \mathrm{u}}{\partial \psi}+\frac{\mathrm{w}}{\mathrm{R}_{1}} \\
& \widehat{\mathrm{e}}_{22}=\frac{1}{\mathrm{R}_{2}} \frac{\partial \mathrm{v}}{\partial \theta}+\frac{\mathrm{w}}{\mathrm{R}_{2}} \\
& \widehat{\mathrm{e}}_{21}=\frac{1}{\mathrm{R}_{1}} \frac{\partial \mathrm{v}}{\partial \psi} \\
& \widehat{\mathrm{e}}_{13}=\frac{1}{\mathrm{R}_{1}} \frac{\partial \mathrm{w}}{\partial \psi}-\frac{\mathrm{u}}{\mathrm{R}_{1}} \\
& \widehat{\mathrm{e}}_{12}=\frac{1}{\mathrm{R}_{2}} \frac{\partial \mathrm{u}}{\partial \theta} \\
& \widehat{\mathrm{e}}_{23}=\frac{1}{\mathrm{R}_{2}} \frac{\partial \mathrm{w}}{\partial \theta}-\frac{\mathrm{v}}{\mathrm{R}_{2}} \\
& \mathrm{k}_{11}=\frac{1}{\mathrm{R}_{1}} \frac{\partial \vartheta}{\partial \psi}+\frac{\chi}{\mathrm{R}_{1}}
\end{aligned}
$$




$$
\begin{aligned}
& \mathrm{k}_{22}=\frac{1}{\mathrm{R}_{2}} \frac{\partial \Psi}{\partial \theta}+\frac{\chi}{\mathrm{R}_{2}} \\
& \mathrm{k}_{12}=\frac{1}{\mathrm{R}_{1}} \frac{\partial \Psi}{\partial \psi} \\
& \mathrm{k}_{21}=\frac{1}{\mathrm{R}_{2}} \frac{\partial \vartheta}{\partial \theta} \\
& \mathrm{k}_{13}=\frac{1}{\mathrm{R}_{1}} \frac{\partial \chi}{\partial \psi}-\frac{\vartheta}{\mathrm{R}_{1}} \\
& \mathrm{k}_{23}=\frac{1}{\mathrm{R}_{2}} \frac{\partial \chi}{\partial \theta}-\frac{\Psi}{\mathrm{R}_{2}}
\end{aligned}
$$

and

$$
\begin{aligned}
& \vartheta=-\left(1+\widehat{\mathrm{e}}_{22}\right) \hat{\mathrm{e}}_{13}+\hat{\mathrm{e}}_{23} \hat{\mathrm{e}}_{12} \\
& \Psi=-\left(1+\hat{\mathrm{e}}_{11}\right) \hat{\mathrm{e}}_{23}+\hat{\mathrm{e}}_{13} \hat{\mathrm{e}}_{21} \\
& \chi=\hat{\mathrm{e}}_{11}+\hat{\mathrm{e}}_{22}+\hat{\mathrm{e}}_{11} \hat{\mathrm{e}}_{22}-\hat{\mathrm{e}}_{12} \hat{\mathrm{e}}_{21}
\end{aligned}
$$




\section{Appendix B}

\section{Fourier Components of the Double Series}

The transverse deflection at the center of shell $\left(\psi=\psi_{0} / 2\right.$ and $\left.\theta=\theta_{0} / 2\right)$ is

given as $\mathrm{w}_{\mathrm{c}}=4 \sum_{\mathrm{n}=0}^{\mathrm{N}} \sum_{\mathrm{m}=0}^{\mathrm{M}} \mathrm{a}_{\mathrm{mn}} \cos \frac{\mathrm{m} \pi}{2} \cos \frac{\mathrm{n} \pi}{2}$

Due to symmetry, $\mathrm{a}_{\mathrm{mn}}=0$ when $\mathrm{n}$ or $\mathrm{m}$ is odd. Therefore for $\mathrm{N}=\mathrm{M}=6$, the center deflection is explicitly given by

$$
\begin{aligned}
\mathrm{w}_{\mathrm{c}}= & 4\left[\mathrm{a}_{00}-\mathrm{a}_{02}+\mathrm{a}_{04}-\mathrm{a}_{06}-\mathrm{a}_{20}+\mathrm{a}_{22}-\mathrm{a}_{24}+\mathrm{a}_{26}\right. \\
& \left.+\mathrm{a}_{40}-\mathrm{a}_{42}+\mathrm{a}_{44}-\mathrm{a}_{46}-\mathrm{a}_{60}+\mathrm{a}_{62}-\mathrm{a}_{64}+\mathrm{a}_{66}\right]
\end{aligned}
$$

The above Fourier components are plotted in Fig. B1. 


\section{Appendix C}

\section{Post-Buckling Analysis of Double Curvature Shell}

The shell described in Section 4 is subjected to a uniformly distributed, quasistatic pressure load. The pressure load increases monotonically from zero to $0.6 \mathrm{MPa}$ at a loading rate of $2.4 \mathrm{MPa} / \mathrm{s}$ or over a time step of $0.25 \mathrm{~s}$. Equations of motion were solved again using MATLAB ode23tb solver with absolute and relative tolerances of $1 \mathrm{e}^{-6}$ and $1 \mathrm{e}^{-4}$, respectively, and $\mathrm{N}=\mathrm{M}=6$. Finite element analysis described in Section 4.2 was also done with the same quasi-static pressure loading. Figure C1 shows a comparison of the center deflection of the plate between predicted and FEA. The shell clearly loses stability at approximately the same pressure load (0.45 $\mathrm{MPa})$ and deflection $(0.9 \mathrm{~mm})$ in both cases.

Table C.1 summarizes predicted buckling pressures from the use of Novozhilov nonlinear shell theory and ABAQUS for other shell geometries. These comparisons serve to validate the analytical model based on Novozhilov nonlinear shell theory.

Table C1 Comparison of analytically predicted buckling pressure with FEA predictions.

\begin{tabular}{|l|l|l|l|}
\hline \multicolumn{1}{|c|}{ Shell Geometry } & $\begin{array}{c}\text { Predicted } \\
\mathrm{P}_{\mathrm{cr}}(\mathrm{MPa})\end{array}$ & $\begin{array}{c}\text { FEA } \\
\mathrm{P}_{\mathrm{cr}}(\mathrm{MPa})\end{array}$ & $\begin{array}{c}\text { \% difference of } \\
\text { predicted to } \\
\text { FEA }\end{array}$ \\
\hline $20 \mathrm{deg}, \mathrm{a} / \mathrm{h}=55.3, \mathrm{R} / \mathrm{h}=158.4$ & 0.382 & 0.379 & 0.8 \\
\hline $20 \mathrm{deg}, \mathrm{a} / \mathrm{h}=110.6, \mathrm{R} / \mathrm{h}=316.8$ & 0.164 & 0.171 & 5.8 \\
\hline $40 \mathrm{deg}, \mathrm{a} / \mathrm{h}=110.6, \mathrm{R} / \mathrm{h}=158.4$ & 0.452 & 0.445 & 1.6 \\
\hline $80 \mathrm{deg}, \mathrm{a} / \mathrm{h}=110.6, \mathrm{R} / \mathrm{h}=79.2$ & 1.581 & 1.550 & 2.0 \\
\hline $80 \mathrm{deg}, \mathrm{a} / \mathrm{h}=221.2, \mathrm{R} / \mathrm{h}=158.4$ & 0.672 & 0.687 & 1.7 \\
\hline
\end{tabular}




\section{References}

1. H.E. Lindberg and A.L. Florence, Dynamic Pulse Buckling, Martinus Nijhoff Publishers, Dordrecht, 1987.

2. G.J. Simitses, Dynamic Stability of Suddenly Loaded Structures, SpringerVerlag, New York, 1990.

3. J. Singer, J. Arbocz and T. Weller, Buckling Experiments: Experimental methods in buckling of thin-walled structures, Vol. 2, Shells, built-up structures, composites and additional topics, John Wiley and Sons, New York, 2002.

4. B. Budiansky and R.S. Roth, Axisymmetric dynamic buckling of clamped shallow spherical shells, in Collected Papers on Instability of Shell Structures, NASA TN D-1510, Washington DC, 1962: 597-606.

5. C.S. Hsu, Equilibrium configurations of a shallow arch of arbitrary shape and their dynamic stability character, Int. J. Nonlinear Mech. 3 (1968) 113-136.

6. J.N. Goodier and I.K. McIvor, The elastic cylindrical shell under nearly uniform radial impulse, Journal of Applied Mechanics 31 (1964) 259-266.

7. J.S. Humphreys, On dynamic snap buckling of shallow arches, AIAA Journal 4 (1965) 878-886.

8. L.J. Ovenshire and I.K. McIvor, On the dynamic snap-through of a shallow cylindrical shell subject to nearly symmetric impulsive loading, Int J. Sol. Struct. 7 (1971): 585-601.

9. N.J. Mallon, R.H.B. Fey, H. Nijmeijer and G.Q. Zhang, Dynamic buckling of a shallow arch under shock loading considering the effects of arch shape, International Journal of Non-Linear Mechanics 41 (2006) 1057-1067. 
10. R. Tanov, A. Tabiei and G.J. Simitses, Effect of static preloading on the dynamic buckling of laminated cylinders under sudden pressure, Mechanics of Composite Materials and Structures 6 (1999) 195-206.

11. A. Schokker, S. Sridharran and A. Kasagi, Dynamic buckling of composite shells. Computers and Structures 59 (1996) 43-53.

12. M.S. Hoo Fatt and S.G. Pothula, Dynamic pulse buckling of composite shells subjected to external blast, Composites Structures 92 (2010) 1716-1727.

13. Y. Gao and M.S. Hoo Fatt, Dynamic pulse buckling of single curvature composite Shells under external blast, Thin-Walled Structures 52 (2012) 149157.

14. Y. Gao and M.S. Hoo Fatt, Local facesheet pulse buckling in a curved, composite sandwich panel, Composite Structures 104 (2013) 249-260.

15. Novozhilov, V. V., Theory of Elasticity (translated from Russian by J.K. Lusher), Pergamon Press, New York, 1961.

16. F. Alijani, M. Amabili, Non-linear vibrations of shells: A literature review fro2003 to 2013, International JournalofNon-LinearMechanics58(2014)233257.

17. M. Amabili, Nonlinear Vibration and Stability of Shells and Plates, Cambridge University Press, New York, NY, 2008

18. J.G. Teng, T. Hong, Nonlinear thin shell theories for numerical buckling predictions, Thin-Walled Structures 31 (1998) 89-115. 
19. K. Maguerre, Zur Theorie der gekrummten Platte grosser Formanderung, in the Proceedings of the Fifth International Congress of Applied Mechanics. New York: Wiley and Sons, (1938) 93-101.

20. E.H. Donnell, A new theory for the buckling of thin cylinders under axial compression and bending, Transactions of ASME 56(1934) 795-806.

21. J.L. Sanders, Nonlinear theories for thin shells. Quarterly Journal of Applied Math 21 (1963) 21-36.

22. W.T. Koiter, On the nonlinear theory of thin elastic shells, in the Proceedings of the Koninklijke Nederlandse Akademie van Wetenschappen, Series B 69(1966) $1-54$.

23. A. Shams, M. Porfiri, Axisymmetric static and dynamic buckling of hollow microspheres, International JournalofNon-LinearMechanics61(2014)19-31.

24. M. Ganapathi, S.S. Gupta, B.P. Patel, Nonlinear axisymmetric dynamic buckling of laminated angle-ply composite spherical caps, Composite Structures 59 (2003) 89-97.

25. M. Amabili, Non-linear vibration of doubly curved shallow shells, Int J NonLinear Mechanics 40 (2005) 683-710.

26. M. Amabili, J.N.Reddy, A new non-linear higher-order shear deformation theory for large-amplitude vibrations of laminated doubly curved shells, Int. J. Non-LinearMech 45(4) (2010)409-418.

27. A. Abe, Y. Kobayashi, G. Yamada, Non-linear vibration characteristics of clamped laminated shallow shells, J Sound \& Vibration 234(3) (2000) 405-426. 
28. J.W. Boh, L.A. Louca, Y.S. Choo, S.E. Mouring, Damage modeling of SCRIMP woven roving laminated beams subjected to transverse shear, Composites Part B 36 (2005) 427-438.

29. P. Kumar, D.S. Stargel and A. Shukla, Effect of plate curvature on blast response of carbon composite panels, Composite Structures 99 (2013) 19-30. 


\section{List of Figures}

Figure 1 Double curvature shell subjected to external pressure pulse loading.

Figure 2 Shell response for $\mathrm{p}_{0}=0.9 \mathrm{MPa}$ and $\tau=1 \mathrm{~ms}$ with various number Fourier components: (a) shell center deflection and (b) deflection profile at $\mathrm{t}=0.9 \mathrm{~ms}$ along $\mathrm{y}=\mathrm{b} / 2$.

Figure 3 Finite element model of double curvature shell.

Figure 4 Comparison of predicted and FEA stable vibration response with $\mathrm{p}_{0}=0.9 \mathrm{MPa}$ and $\tau=1 \mathrm{~ms}:$ (a) shell center deflection and (b) deflection profile at $\mathrm{t}=0.9 \mathrm{~ms}$ along $\mathrm{y}=\mathrm{b} / 2$.

Figure 5 Determination of $\mathrm{p}_{\mathrm{cr}}$ when $\tau=1 \mathrm{~ms}$ : (a) shell response with varying peak pressures and (b) stability curve indicating snap-through buckling.

Figure 6 Dynamic stability of Woven Roving E-Glass/Vinyl Ester shell: (a) critical buckling curve and (b) stability curves at $0.1,1,10$ and $100 \mathrm{~ms}$.

Figure 7 Woven E-Glass/Vinyl Ester shell with fixed radius of curvature and various span (angular extent changes with span): (a) shell geometry and (b) critical buckling curves.

Figure 8 Woven E-Glass/Vinyl Ester shell with fixed span and various radius of curvature (angular extent changes with radius of curvature): (a) shell geometry and (b) critical buckling curves.

Figure 9 Deformation and buckling modes of shells $(\mathrm{R} / \mathrm{h}=158.4)$ with a pulse decay constant of $1 \mathrm{~ms}$ : (a) a/h=55.3, $20 \mathrm{deg}$, (b) a/h=110.6, $40 \mathrm{deg}$, and (c) $\mathrm{a} / \mathrm{h}=221.2,80$ deg.

Figure 10 Deformation and buckling modes of shells $(\mathrm{a} / \mathrm{h}=110.6)$ with a pulse decay constant of $1 \mathrm{~ms}$ : (a) $\mathrm{R} / \mathrm{h}=316.8,20 \mathrm{deg}$, (b) $\mathrm{R} / \mathrm{h}=158.4,40 \mathrm{deg}$, and (c) $\mathrm{R} / \mathrm{h}=79.2,80$ deg.

Figure B1 Fourier components of shell center deflection for $\mathrm{p}_{0}=0.9 \mathrm{MPa}$ and $\tau=1 \mathrm{~ms}$ when $\mathrm{N}=\mathrm{M}=6$.

Figure C1 Load-deflection response of shell under uniformly-distributed, quasi-static pressure load (post-buckling analysis). 


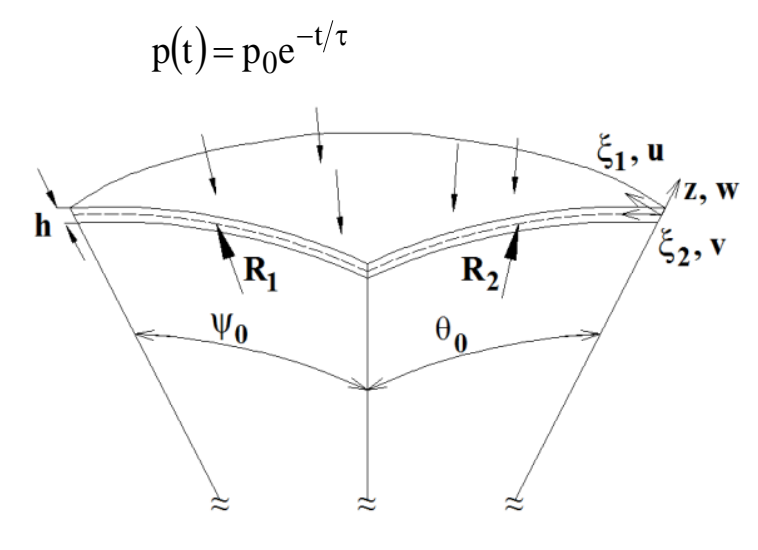

Figure 1 Double curvature shell subjected to external pressure pulse loading.$$
\mathrm{p}(\mathrm{t})=\mathrm{p}_{0} \mathrm{e}^{-\mathrm{t} / \tau}
$$

\section{Figur}

(1) 


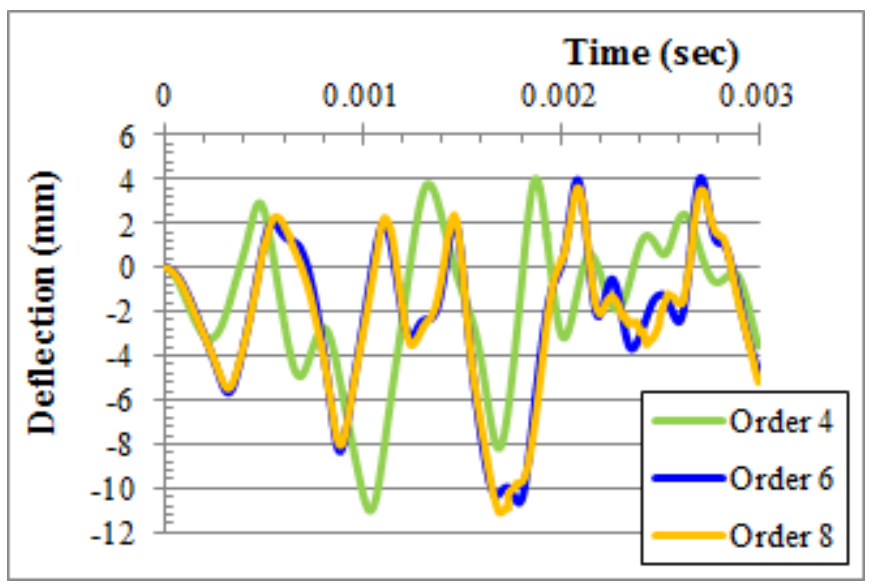

(a)

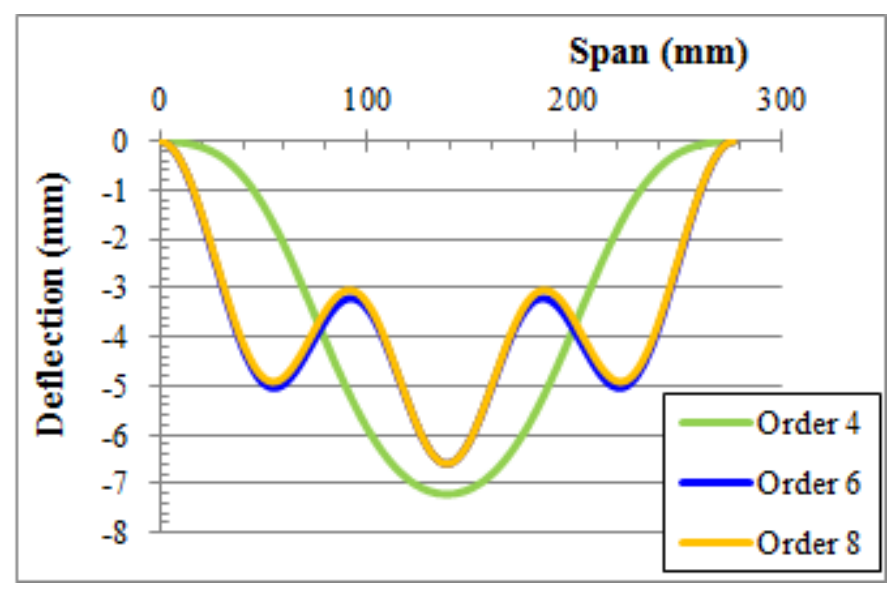

Figure 2 Shell response for $\mathrm{p}_{0}=0.9 \mathrm{MPa}$ and $\tau=1 \mathrm{~ms}$ with various number Fourier components: (a) shell center deflection and (b) deflection profile at $\mathrm{t}=0.9 \mathrm{~ms}$ along $\mathrm{y}=\mathrm{b} / 2$. 


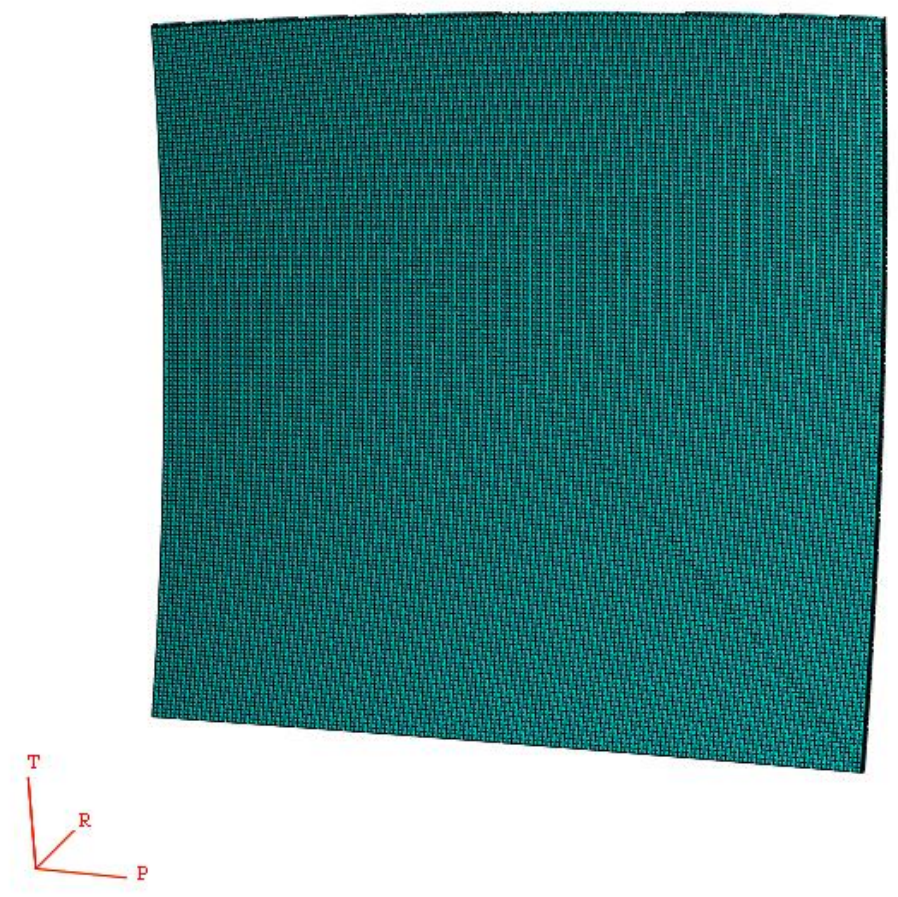

Figure 3 Finite element model of double curvature shell. 


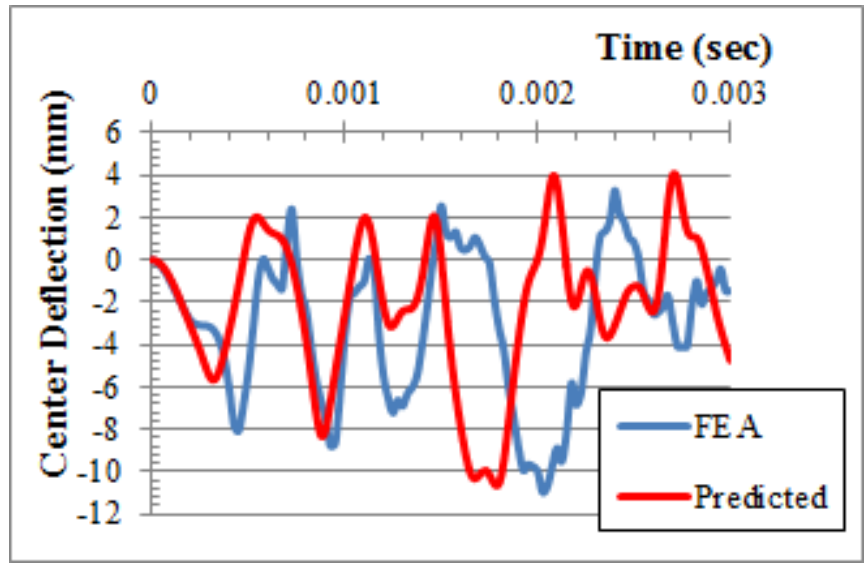

(a)

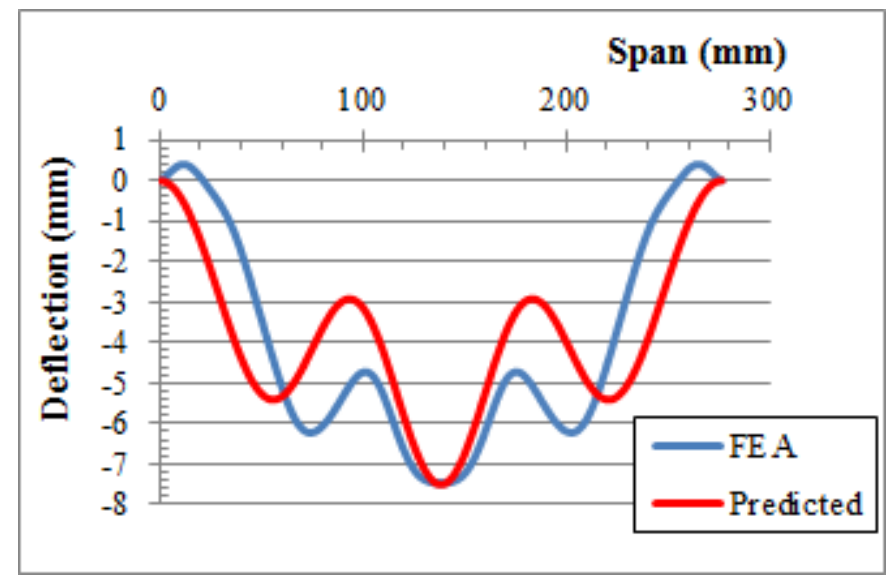

(b)

Figure 4 Comparison of predicted and FEA stable vibration response with $\mathrm{p}_{0}=0.9 \mathrm{MPa}$ and $\tau=1 \mathrm{~ms}:$ (a) shell center deflection and (b) deflection profile at $\mathrm{t}=0.9 \mathrm{~ms}$ along $\mathrm{y}=\mathrm{b} / 2$. 


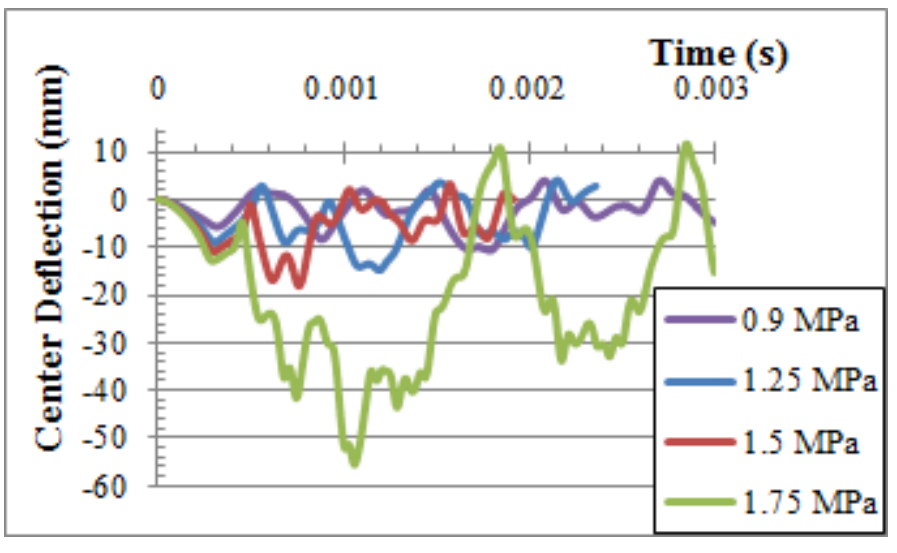

(a)

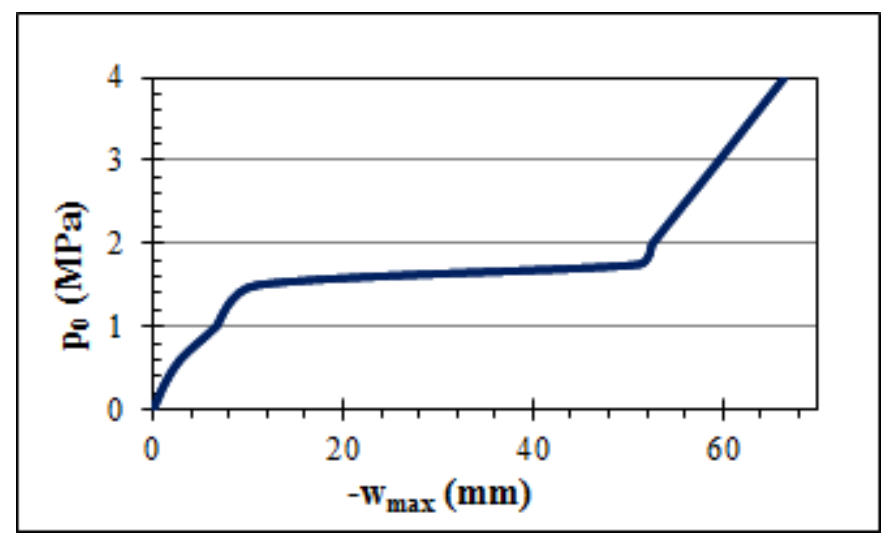

(b)

Figure 5 Determination of $\mathrm{p}_{\mathrm{cr}}$ when $\tau=1 \mathrm{~ms}$ : (a) shell response with varying peak pressures and (b) stability curve indicating snap-through buckling. 


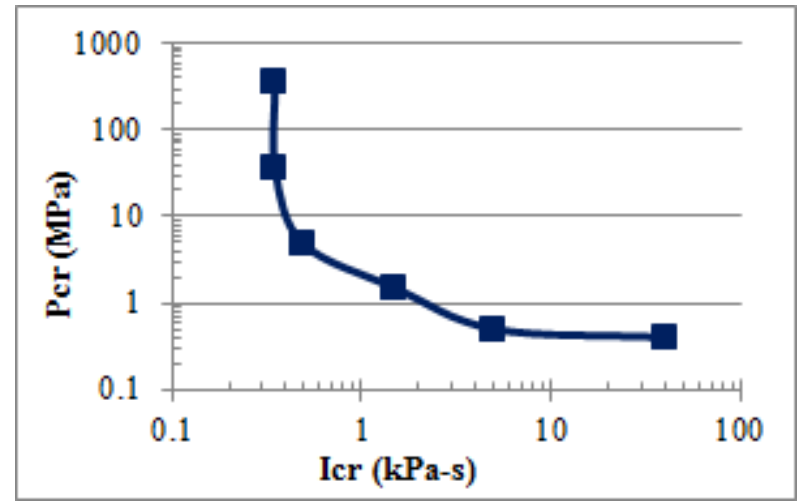

(a)

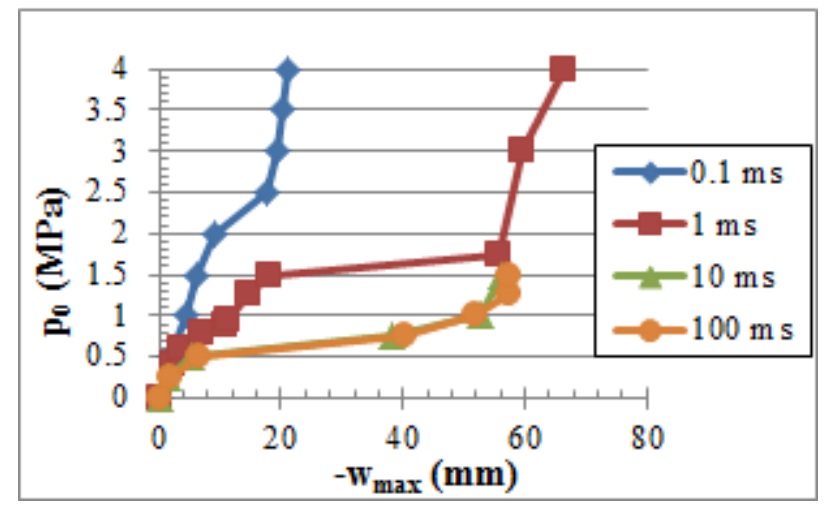

(b)

Figure 6Dynamic stability of Woven Roving E-Glass/Vinyl Ester shell: (a) critical buckling curve and (b) stability curves at 0.1, 1, 10 and $100 \mathrm{~ms}$. 


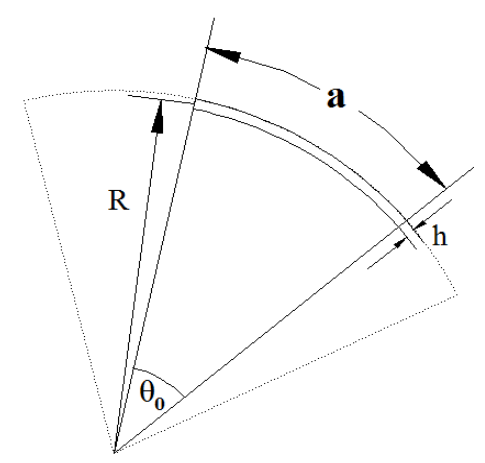

(a)

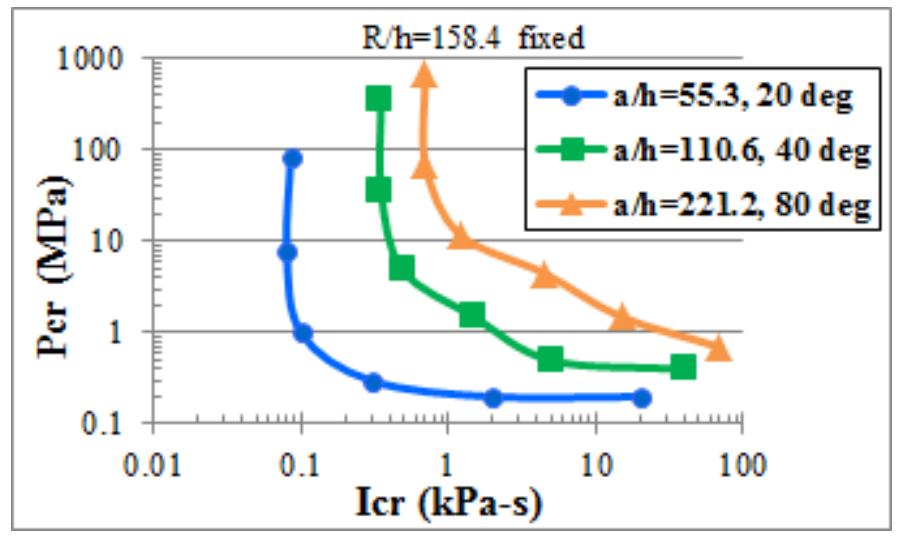

(b)

Figure 7 Woven E-Glass/Vinyl Ester shell with fixed radius of curvature and various span (angular extent changes with span): (a) shell geometry and (b) critical buckling curves. 


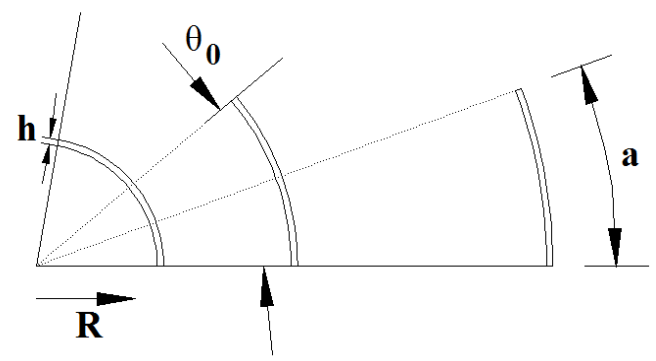

(a)

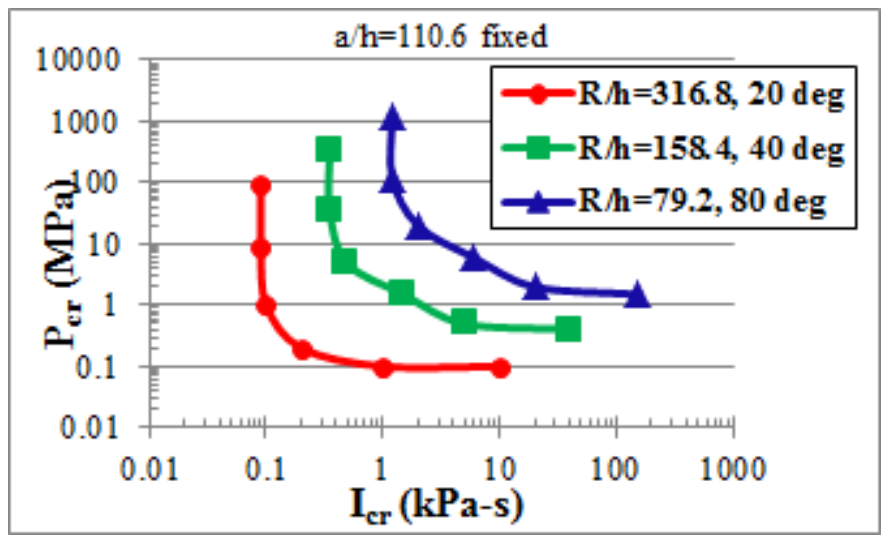

(b)

Figure 8 Woven E-Glass/Vinyl Ester shell with fixed span and various radius of curvature (angular extent changes with radius of curvature): (a) shell geometry and (b) critical buckling curves. 

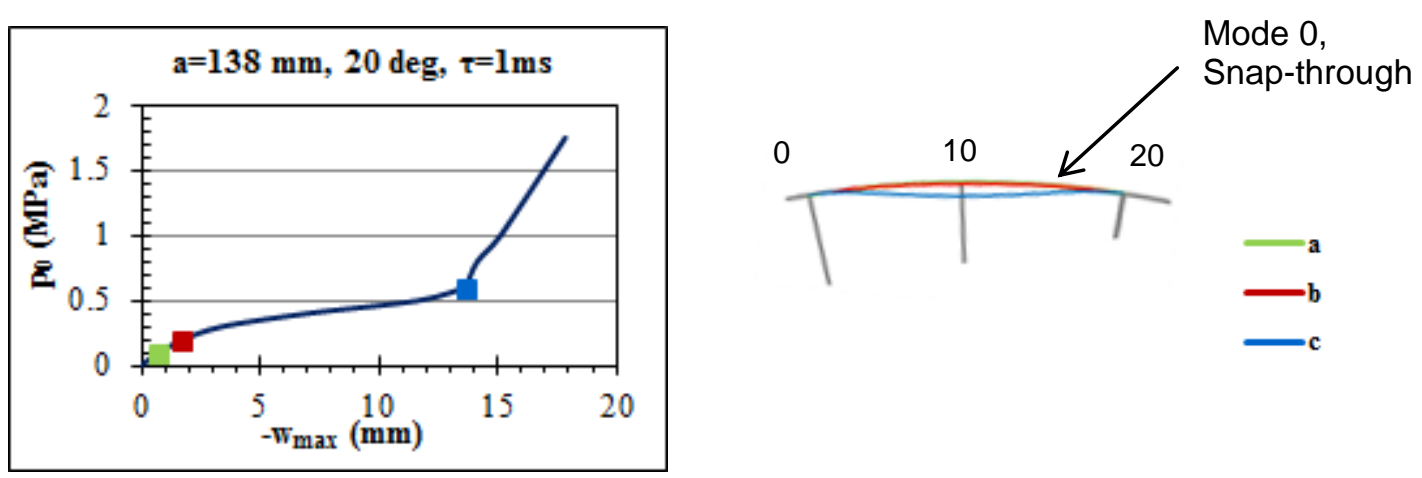

(a)
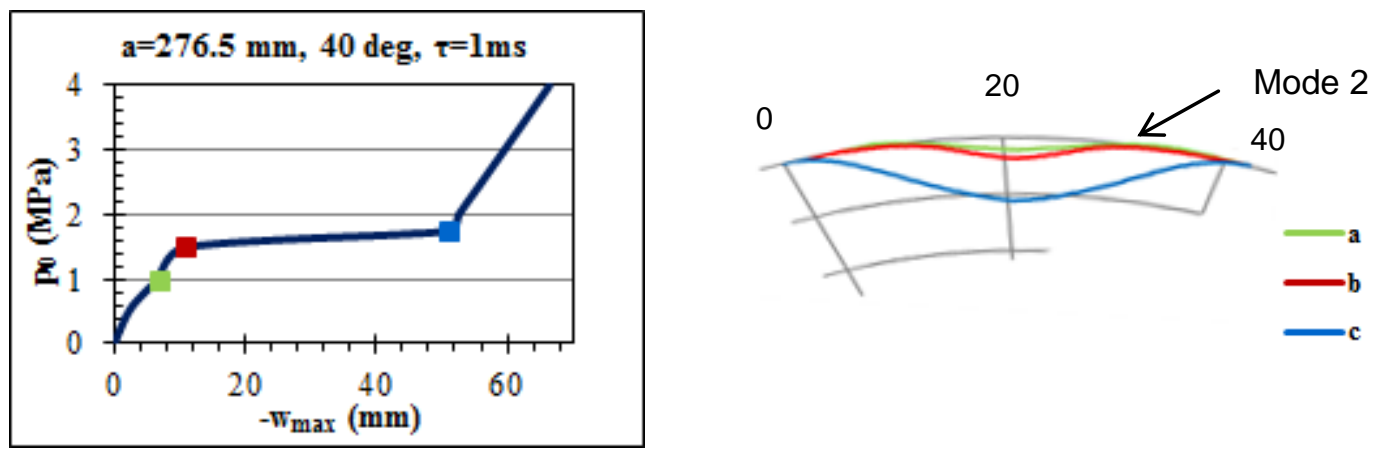

(b)
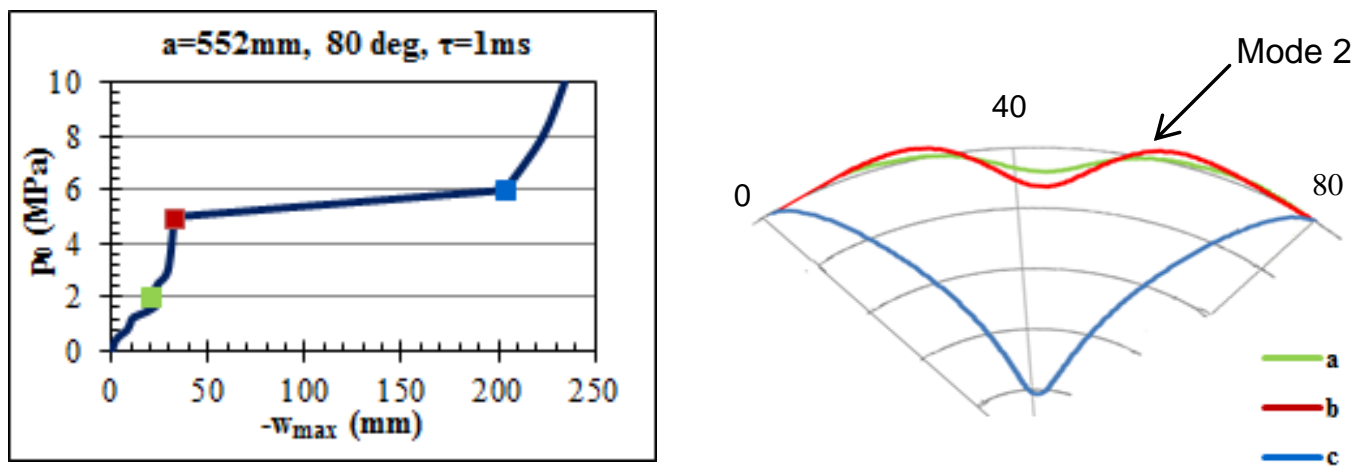

(c)

Figure 9 Deformation and buckling modes of shells $(\mathrm{R} / \mathrm{h}=158.4)$ with a pulse decay constant of $1 \mathrm{~ms}$ : (a) a/h=55.3, $20 \mathrm{deg}$, (b) a/h=110.6, $40 \mathrm{deg}$, and (c) $\mathrm{a} / \mathrm{h}=221.2,80$ deg. 

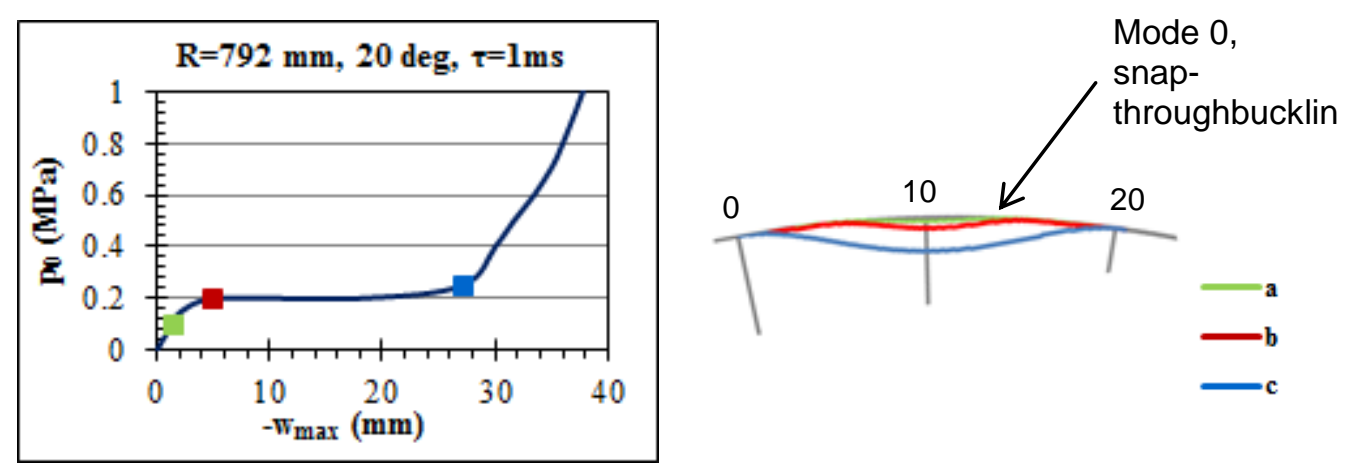

(a)
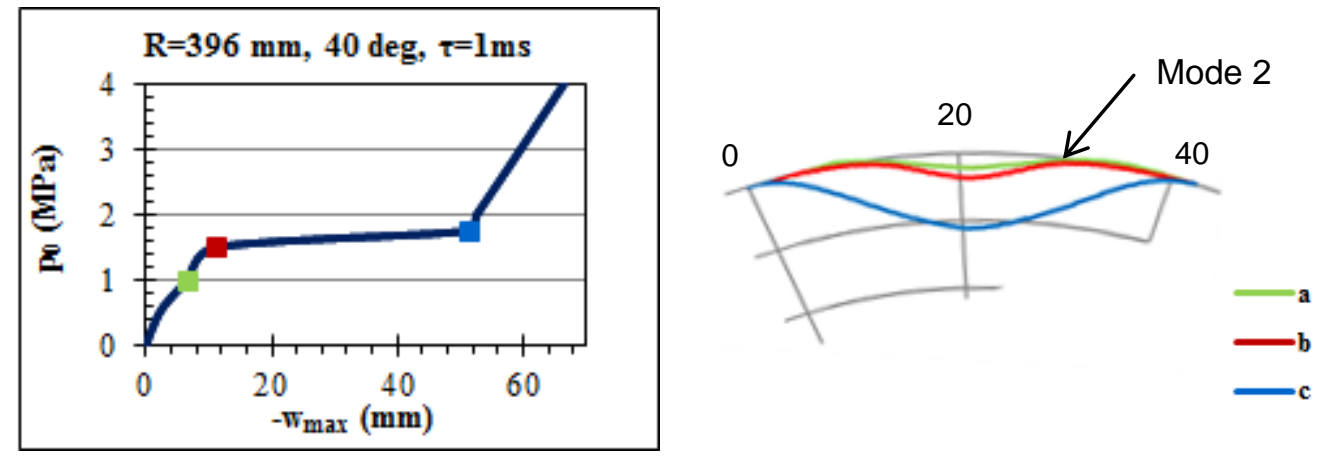

(b)
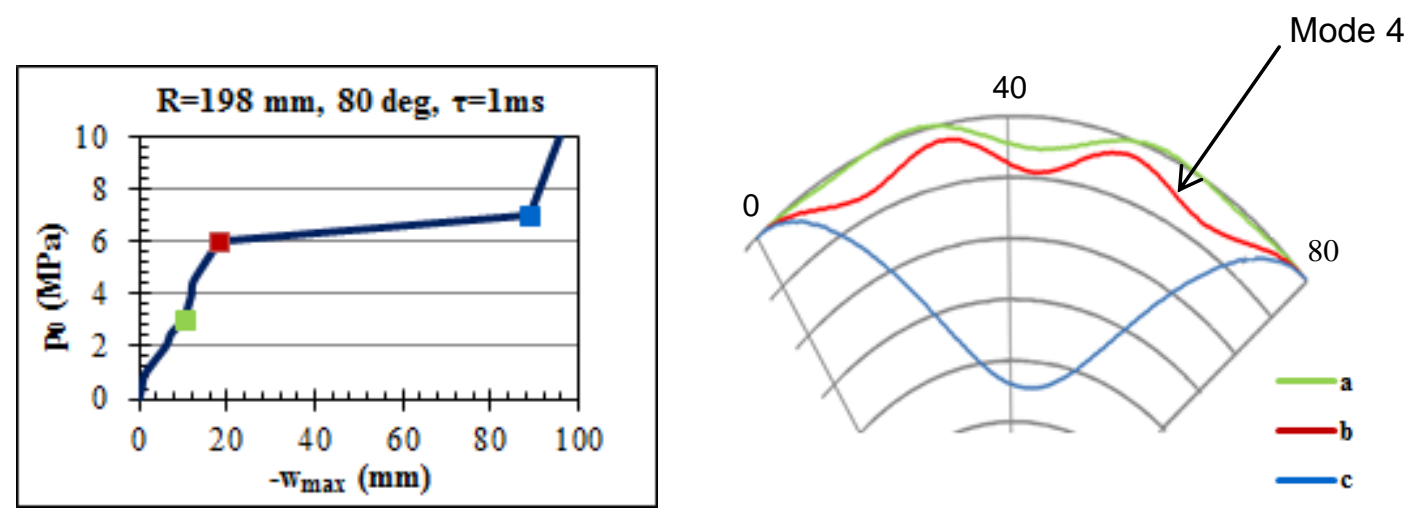

(c)

Figure 10 Deformation and buckling modes of shells $(\mathrm{a} / \mathrm{h}=110.6)$ with a pulse decay constant of $1 \mathrm{~ms}$ : (a) $\mathrm{R} / \mathrm{h}=316.8,20 \mathrm{deg}$, (b) $\mathrm{R} / \mathrm{h}=158.4,40 \mathrm{deg}$, and (c) $\mathrm{R} / \mathrm{h}=79.2,80$ deg. 


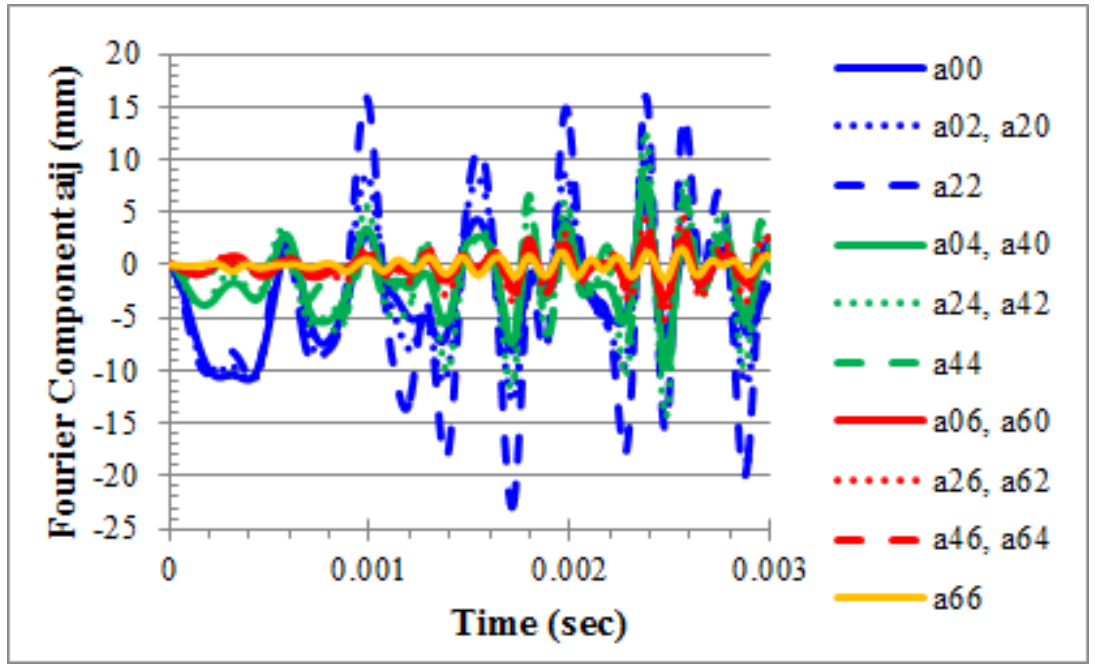

Figure B1 Fourier components of shell center deflection for $\mathrm{p}_{0}=0.9 \mathrm{MPa}$ and $\tau=1 \mathrm{~ms}$ when $\mathrm{N}=\mathrm{M}=6$. 


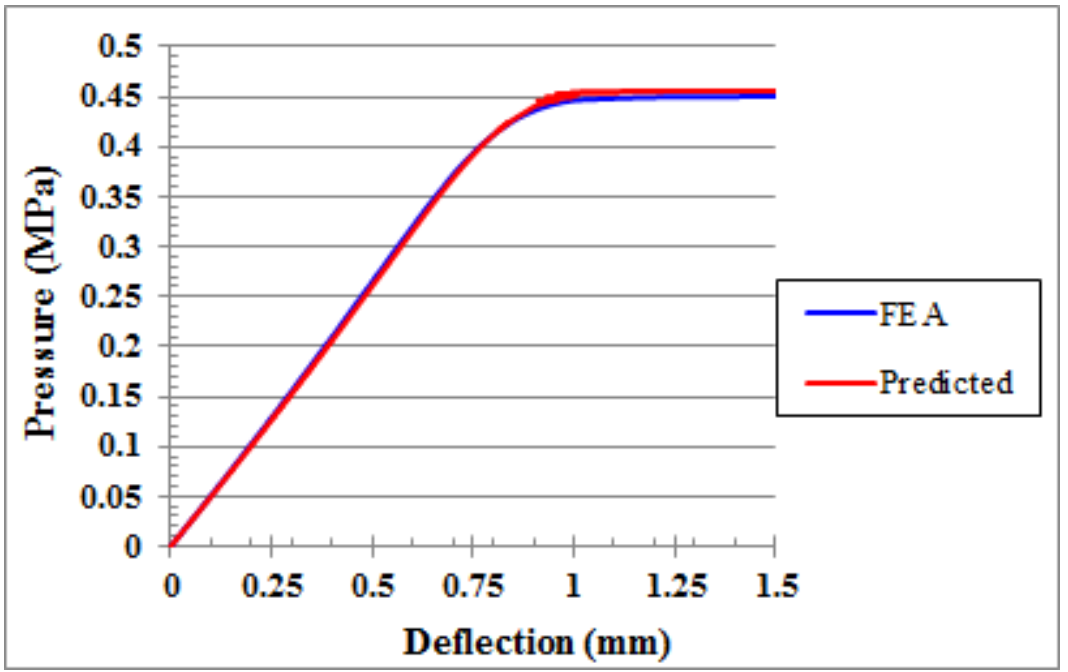

Figure C1 Load-deflection response of shell under uniformly-distributed, quasi-static pressure load (post-buckling analysis). 